\title{
Performance of RegCM2.5/NCAR-CSM Nested System for the Simulation of Climate Change in East Asia Caused by Global Warming
}

\author{
By Hisashi Kato, Keiichi Nishizawa, Hiromaru Hirakuchi, \\ Shinji Kadokura, Naoko Oshima \\ Central Research Institute of Electric Power Industry, Tokyo, Japan \\ and \\ Filippo Giorgi \\ Abdus Salam ICTP, Trieste, Italy \\ (Manuscript received 30 September 1999, in revised form 31 October 2000)
}

\begin{abstract}
Regional climate in East Asia under $1 \mathrm{CO}_{2}$ and $2 \mathrm{CO}_{2}$ conditions, was simulated for continuous 10-year periods by the RegCM2.5 developed by NCAR, using the output of a $\mathrm{CO}_{2}$ transient run from NCAR-CSM as lateral and surface boundary conditions in order to evaluate the performance of the nested system for the use of climate change simulation caused by global warming for that region. In this study, January and June climates were analyzed.

Through the validation of the simulated present climate, it was clarified that the typical precipitation phenomenon which occurs on the northwestern side of Japan during the winter monsoon is relatively well reproduced in the RegCM, but weakly in the CSM. It indicates that the RegCM is essential for the prediction of regional climate change for the East Asia region. Although the present climate reproduced by the RegCM has some marked biases, e.g. the large cold bias in the higher latitude in winter and the missing of the Bai-u front in mainland China, they are mainly due to the overestimation of sea ice area, and the northward shift of the NPH (North Pacific High) in the CSM, respectively. The SST bias in the CSM significantly contributes to the surface air temperature bias on the coast.

In the climate change simulations, the large-scale distributions of SLP and temperature in the RegCM bear a resemblance to those of the CSM in both months. On the other hand, the regional scale precipitation change patterns are different between the RegCM and the CSM in June, because the precipitation band near Japan is well reproduced in the RegCM both in the $1 \mathrm{CO}_{2}$ and the $2 \mathrm{CO}_{2}$ climate. In this simulation, some notable climate change features are found, such as the temperature increase at higher latitudes in January, or intensification of the NPH extending to the southwest in June. Although these changes are statistically significant, they are mainly influenced by the bias in the CSM because the changes occur over the bias region, and their magnitudes do not necessarily exceed the bias of the simulated present climate. From these results, it should be stressed that it is of utmost importance that the AOGCM information is of good quality in the prediction of regional climate change.
\end{abstract}

Corresponding author: Hisashi Kato, Central Research Institute of Electric Power Industry, 2-11-1 Iwado Kita, Komae-shi, Tokyo 201-8511, Japan. E-mail: kato@criepi.denken.or.jp

(C)2001, Meteorological Society of Japan

\section{Introduction}

Recently, the global warming problem due to the increase of greenhouse gases such as $\mathrm{CO}_{2}$ has been recognized as a global environmental issue, and 
great efforts have been made by numerous scientists world wide to clarify the features of climate change caused by global warming and to evaluate its effects (IPCC 1990a, b, 1992, 1996). Although the importance of earlier evaluations of the impact of climate change has been pointed out, the climate change scenario (data) on a regional scale required for the assessment has not been supplied. In some cases, the researchers have no alternative but to use the general circulation model (GCM) results with coarse resolution. Although the ideal choice is to use a high-resolution GCM or global climate model for the construction of a regional climate change scenario, much computer time and improvements of physical process parameterization corresponding to high resolution are required to complete such a calculation with a resolution of about 20 to $30 \mathrm{~km}$. Therefore, the method of using the GCM/RegCM (regional climate model) nesting technique is spotlighted to interpret the results of the coarse-resolution GCM into a regional scale (Giorgi and Mearns 1991).

The study of the RegCM was begun by Dickinson et al. (1989), and Giorgi and Bates (1989). In the early stage, the NCAR-RegCM was developed/improved and applied to $2 \mathrm{CO}_{2}$ equilibrium experiments worldwide (Giorgi et al. 1994; Mearns et al. 1995; Marinucci and Giorgi 1992; Giorgi et al. 1992; Verdecchia et al. 1994; Hirakuchi and Giorgi 1995). Recently those results and some new approaches were summarized by Giorgi and Mearns (1999). In this decade, other limited area models have been developed (e.g., Giorgi and Mearns 1999): the climate version of the Colorado State University Regional Atmospheric Modeling System (CSU/RAMS); the Canadian regional climate model; the Commonwealth Science and Industrial Research Organization (CSIRO) DARLAM; the Max-Planck-Institute/Danish Meteorological Institute HIRHAM; the United Kingdom Meteorological Office unified model; and, the Regional Climate Model of the Meteorological Research Institute/Japan Meteorological Agency (MRI/JMA). The vigorous intercomparison studies of the regional climate models have also been conducted (e.g., Christensen et al. 1997; McGregor 1997; Leung et al. 1999).

For the East Asia region, the RegCM has been applied through development and improvement (Kida et al. 1991; Liu et al. 1994; Sasaki et al. 1995; Fukutome et al. 1999; Kato et al. 1999; Leung et al. 1999). Although a study of the $2 \mathrm{CO}_{2}$ equilibrium experiment was conducted by Hirakuchi and Giorgi (1995), their $2 \mathrm{CO}_{2}$ results are not intended to provide a climate change scenario, but only to illustrate the sensitivity of the model to different forcing because of the uncertainties in the control simulations of the GCM.

The authors have conducted a series of studies in order to simulate regional climate change in East Asia caused by global warming. They improved the RegCM through comprehensive evaluation of the model (Kato et al. 1999; Nishizawa and Giorgi 1998; Giorgi et al. 1999). Another group of our Institute carried out the $\mathrm{CO}_{2}$ transient run (125year run) using the NCAR-CSM (climate system model) (Maruyama et al. 1997), the results of which are used for the nesting simulation as lateral and surface boundary conditions.

In this study, regional climate in East Asia for $1 \mathrm{CO}_{2}$ and $2 \mathrm{CO}_{2}$ climates was simulated for continuous 10-year periods by the RegCM2.5 developed by NCAR, using the output of the $\mathrm{CO}_{2}$ transient run from NCAR-CSM as the lateral and surface boundary conditions. January and June climates, both of which include typical precipitation events in Japan, are analyzed mainly focusing on the spatial distribution patterns of surface air temperature and precipitation, using not only monthly data but also daily data. However, some biases are found in the present climate simulated by the CSM, which will be examined later. Furthermore, it should be noted that the effect of sulfate aerosols is not considered in the $\mathrm{CO}_{2}$ transient run and also in the RegCM simulation. Then, these two 10-year simulations are not intended to provide actual predictions of climate change, but to clarify the problems of this nesting method in the prediction of regional climate change in East Asia, i.e., the purpose of this study is almost the same as those of the regional climate change simulation studies recently conducted in the world (Jones et al. 1997; Giorgi et al. 1997, 1998; Renwick et al. 1998; Deque et al. 1998; Laprise et al. 1998; Leung and Ghan 1999).

In Section 2, descriptions of RegCM2.5 and the experimental design are given. The simulated present climates for both January and June are examined and evaluated through a comparison with the observed data in Section 3. The performance/ problem of using this nesting method for the prediction of regional climate change in East Asia are discussed through a comparison of the simulated climate change results of RegCM and CSM, and through the examination of the causes of the cli- 
mate changes in Section 4. The main results are summarized in Section 5 .

\section{Description of RegCM2.5 and experimental design}

The regional climate model used in this study (RegCM2.5) is an improved version of the NCAR RegCM2 (Giorgi et al. 1993a, b). It is based on a hydrostatic grid point limited area model: the Penn State/NCAR Mesoscale Model version 4 (MM4) of Anthes et al. (1987). The RegCM2.5 has been developed by incorporating the CCM3 radiation model (Kiehl et al. 1996) into the MM4 dynamical framework. We have made substantial modifications to the RegCM2 in order to obtain better similarities to the observed climate. Most of them are concerned with the cloud diagnosis scheme and the parameterization scheme for solar radiative properties of partial clouds. The details of our model improvements and their climatic effects are described by Nishizawa and Giorgi (1998) and Giorgi et al. (1999).

The parameterization scheme for large-scale condensation in the RegCM2.5 is a simplified explicit moisture scheme (Giorgi and Shields 1999) which predicts water vapor and cloud water contents, but not rainwater content. The cumulus convection scheme is a slightly modified version of the Kuotype scheme developed by Anthes (1977). The planetary boundary layer (PBL) processes are parameterized according to Holtslag et al. (1990). The parameterization scheme for land surface processes is the Biosphere-Atmosphere Transfer Scheme (BATS) of Dickinson et al. (1993), in which atmospheric conditions near the earth's surface are calculated.

The RegCM has a horizontal resolution (grid point spacing) of $50 \mathrm{~km}$, and 14 atmospheric layers from the surface up to $80 \mathrm{hPa}$ with unequal sigma thicknesses. It covers a horizontal domain of 5850 $\mathrm{km}(\mathrm{E}-\mathrm{W}) \times 5100 \mathrm{~km}(\mathrm{~N}-\mathrm{S})$ with a center at $35^{\circ} \mathrm{N}$, $126^{\circ} \mathrm{E}$. In Fig. 1a and 1b, the model topography of the RegCM, and that of the CSM used in the $\mathrm{CO}_{2}$ transient run, are compared in our simulation domain. The lateral and surface boundary conditions were supplied at 6-hour intervals using the output data from the $\mathrm{CO}_{2}$ transient run of the NCARCSM with a horizontal resolution of T42. The lateral boundary conditions in a "buffer" zone with a 26-grid point width were given to the RegCM by the relaxation procedure described by Giorgi et al. (1993b). For the surface boundary condi-
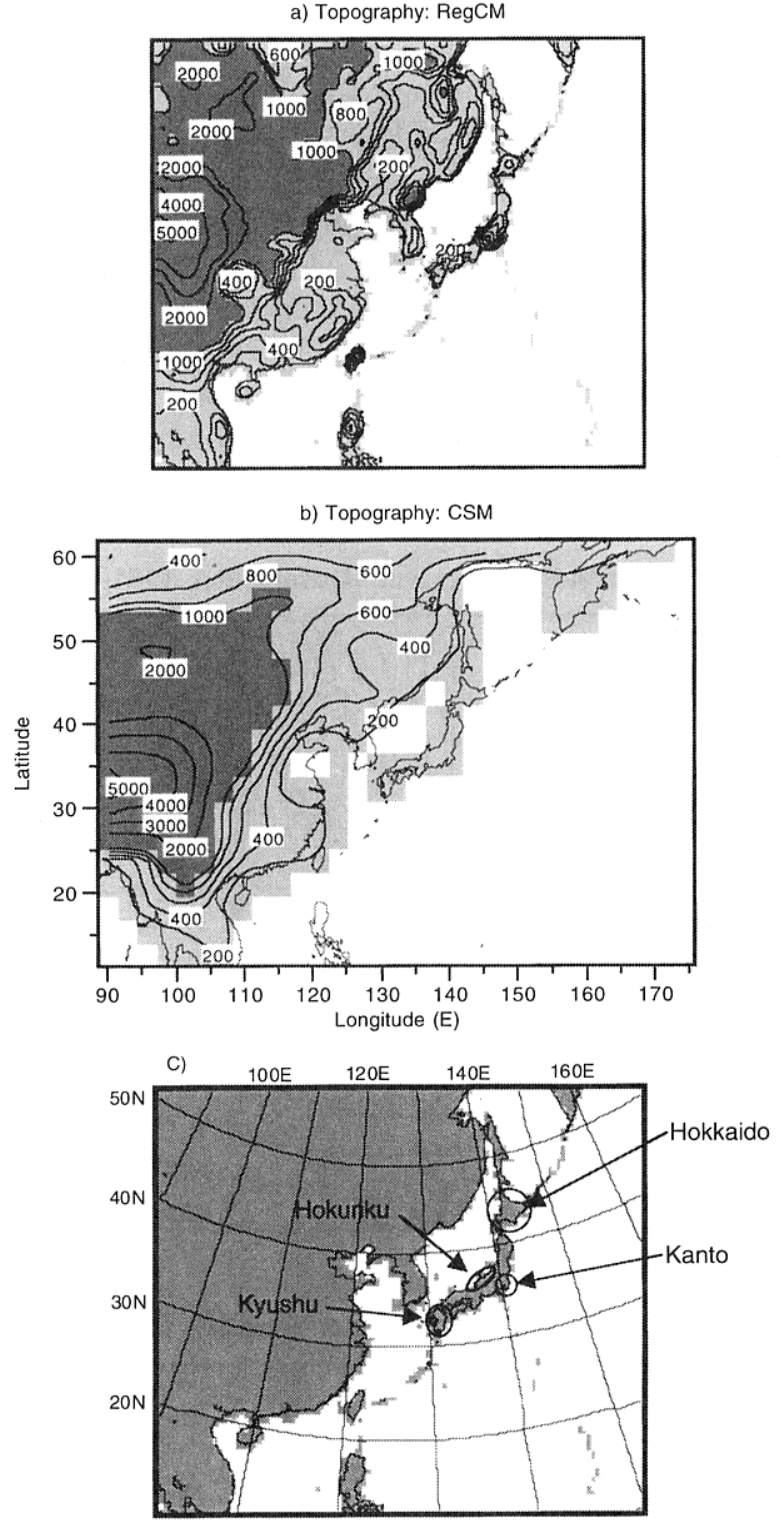

Fig. 1. Topography for East Asia in a) the RegCM with the grid spacing of $50 \mathrm{~km}$ and b) the CSM with the horizontal resolution of T42. Contours are drawn every $200 \mathrm{~m}$ from 0 to $1000 \mathrm{~m}$ (MSL) and every $1000 \mathrm{~m}$ above $1000 \mathrm{~m}$ (MSL). The map used in the RegCM was drawn by Lambert Conformal. c) Location of the Japanese four districts used in the analysis. See the text for detail.

tion, the sea surface temperature (SST hereafter) data of the ocean model in the CSM are interpolated to the ocean area of the RegCM.

The description of the CSM and the $\mathrm{CO}_{2}$ tran- 
sient run are summarized by Maruyama et al. (1997). The CSM, which is a non flux-correction model, was evaluated through a 300-year control run (Boville and Gent 1998) in which no identifiable trends in the surface temperature were found, i.e., $0.03{ }^{\circ} \mathrm{C} / 100$ years. In the transient run, $\mathrm{CO}_{2}$ concentration increased for 115 years (from the model year Y25 to Y140) compounding at 1\%/year from the base level at 1990 (355 ppmv) after a 10-year run (Y15 to Y24) of a constant level. It reaches double the base level after 70 model years and triple at the end of the transient run. We de-

a) Sea Level Pressure: Jan. (Observation: 1961-1990)

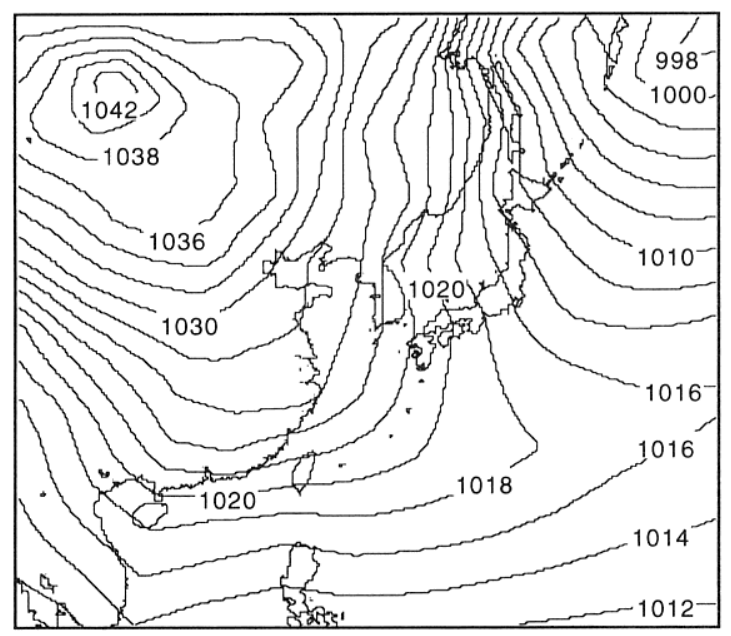

c) Sea Level Pressure: Jan. (RegCM: 1CO2)

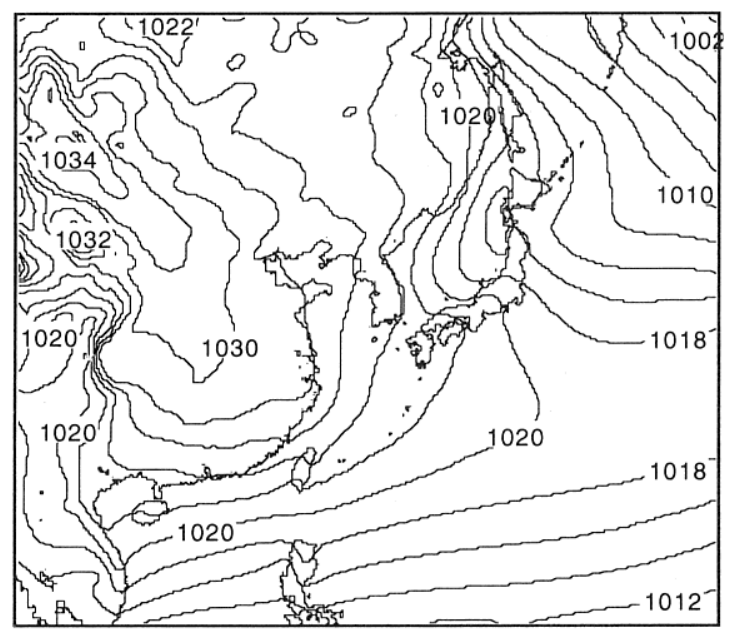

fined the $1 \mathrm{CO}_{2}$ climate as the 10 years from Y15 to $\mathrm{Y} 24$, and the $2 \mathrm{CO}_{2}$ climate from Y95 to Y104, respectively. The continuous 10 -year-period CSM data for both $1 \mathrm{CO}_{2}$ and $2 \mathrm{CO}_{2}$ are used for the RegCM simulation as lateral and surface boundary conditions.

\section{Validation of the reproduced present climate}

\subsection{Climate in January}

a. Sea Level Pressure

In Fig. 2, the 10-year mean sea level pressure

b) Sea Level Pressure: Jan. (CSM: 1CO2)

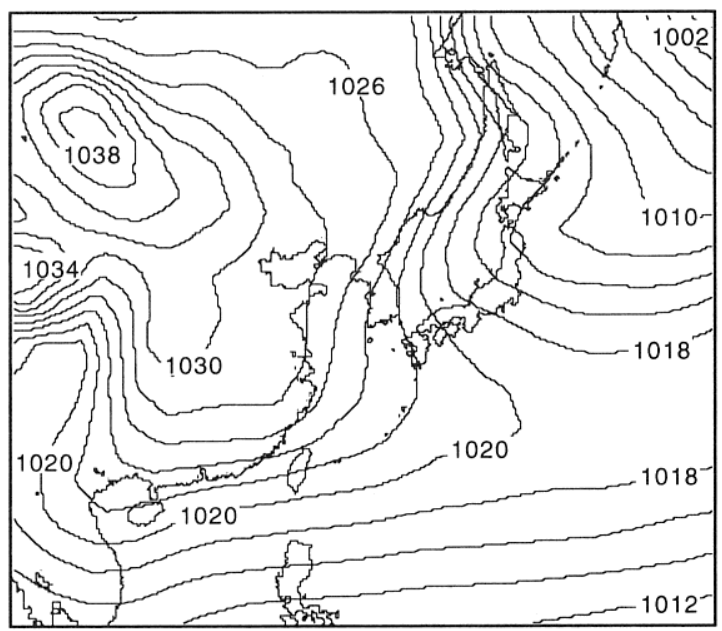

d) Sea Level Pressure: Jan. (RegCM-Obs.)

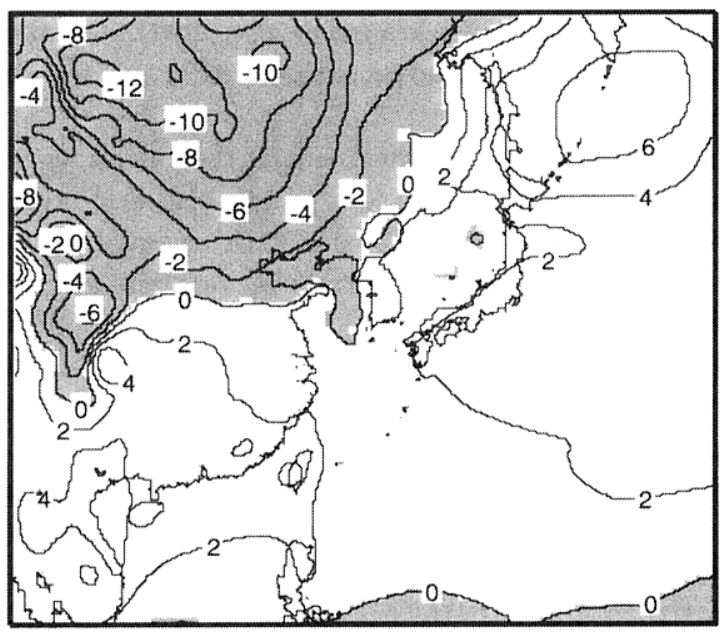

Fig. 2. a) Observed SLP (NCAR: 1961-1990), and 10-year mean sea level pressure simulated by b) the CSM and c) the RegCM in January for $1 \mathrm{CO}_{2}$ climate. d) The SLP bias in the RegCM. The areas with negative bias are hatched. Units are hPa. Observed and CSM data are interpolated into the RegCM grid. o..... 
(SLP hereafter) fields in January simulated by the RegCM and the CSM are compared with the 30year mean observed data (NCAR data set: 19611990) with the horizontal resolution of $5^{\circ} \times 5^{\circ}$. It should be noted that these data are compared on the RegCM grid. Although the observed winter SLP pattern is generally well reproduced in the synoptic scale both in the RegCM and the CSM, the intensities of the Siberian High and the cyclones of the western edge of the Aleutian Low are weakly simulated in the models. This result indicates that the winter monsoon is weakly reproduced in the models. The smoother CSM topography seems to be a cause of the weakly simulated Siberian High since Manabe and Terpstra (1974) indicated from their model simulations that the Tibetan Plateau plays an important role in the development of the Siberian High by its dam effect of the cold air. The reason for the weaker cyclones is mainly due to the overestimation of the sea ice area in the CSM (Weatherly et al. 1998; Maruyama et al. 1997), which suppresses the heat flux from the warmer sea surface. The insufficient or deviated jet stream seems to be another reason for these SLP biases. However, it was confirmed that the intensity and the axes of the strong wind on both the $850 \mathrm{hPa}$ and the $500 \mathrm{hPa}$ surface in the CSM are almost the same as those of observed winds, except the slight northward shift of their axes by only two to three degrees (Kadokura et al. 1998).

In Fig. 2, the isobar rotated counterclockwise in the model compared to the observation over Japan. It is due to the overprediction of the intensity or the frequency of cyclones over the Sea of Japan where the SST has notable warm bias (See Fig. 3). By the influence of more frequent cyclones, the 10year mean wind direction is slightly different in the lower troposphere between the model results and the observation, i.e., the wind shear in the lower troposphere caused by the cold wind from the continent are obscure in the model. However, during the peak period of the winter monsoon, the isobar has the direction of NW-SE over Japan and the wind shear also exists. This feature will be discussed again in Section 3.1.c in relation to the analysis of precipitation.

\section{b. Surface air temperature}

In Fig. 3, the 10-year mean of surface air temperature in January simulated by the RegCM, and of the surface temperature simulated by the CSM, are compared with the 30 -year mean observed surface air temperature from the NCAR data set (19661995 ) with the horizontal resolution of $5^{\circ} \times 5^{\circ}$. Over the land, marked negative and positive biases are found in the RegCM results on the Tibetan Plateau and northern China, respectively. The former biases are mainly due to the height difference between the real and the model topography. The latter seems to be partly caused by the insufficient model ability to simulate the cooling effect in the basin (Kato et al. 1999) because the locations of the peak of the biases correspond to the basins. Although the biases are smaller over the other regions, a detailed comparison is difficult due to the difference between the real and the model topography.

Over the ocean, there is a large negative bias on the eastern Okhotsk Sea and positive bias over the Sea of Japan in the RegCM results. The negative bias over the Okhotsk Sea is mainly due to the overestimation of the area of sea ice in the CSM results mentioned before. It reaches $10^{\circ} \mathrm{C}$ over the east Okhotsk Sea where the sea surface is unrealistically covered by sea ice in the CSM. The warm bias in the Sea of Japan, mentioned in Section 3.1.a, is partly due to interpolation error from the NCAR data set because the horizontal resolution of the NCAR data set is too coarse to be used for comparison near the coastline. When we compare the SST data of the CSM results (data before the interpolation into RegCM grid) to that from the Geophysical Review compiled by the JMA, the biases are about 1 to $3{ }^{\circ} \mathrm{C}$ over the center to the south of the Sea of Japan. The bias of the air temperature is small near the lower troposphere (i.e., about $2{ }^{\circ} \mathrm{C}$ at $1000 \mathrm{hPa}$ surface) at Wajima in Hokuriku (See Fig. 1c for the location), where the air temperature is influenced by the SST of the Sea of Japan during the winter monsoon. The weak negative bias over the ocean in the southern region of the domain is caused by the SST bias in the CSM, which might be due to the fact that the ocean currents are not realistically reproduced because the Philippines are not represented as the land, but as the ocean in the OGCM.

For the further validation of the performance of the RegCM, the simulated 10-year mean surface air temperature over Japan with complex topography is directly compared to the observed 30-year mean data compiled by the JMA at the meteorological stations. Four districts which have typical local climate conditions in Japan are selected for the comparison of the area mean: Hokkaido (northern 
a) Surface Air Temp.: Jan. (Observation: 1966-1995)

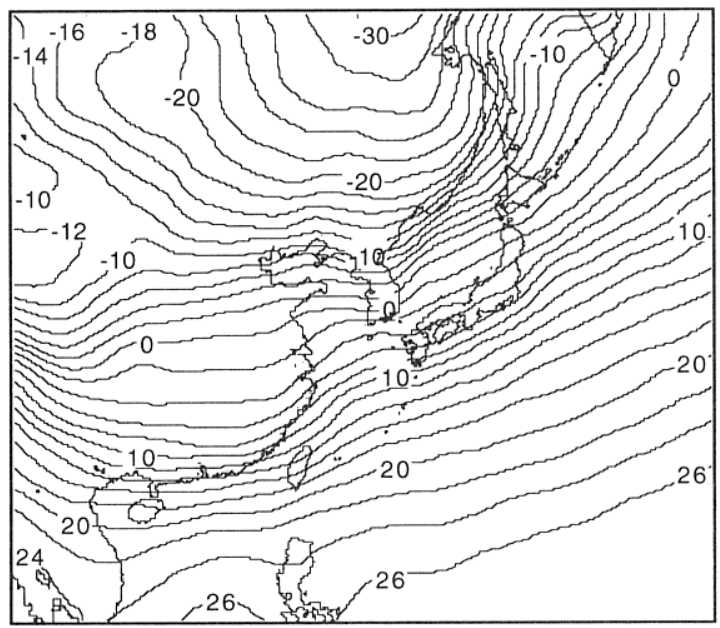

c) Surface Air Temp.: Jan. (RegCM: 1CO2)

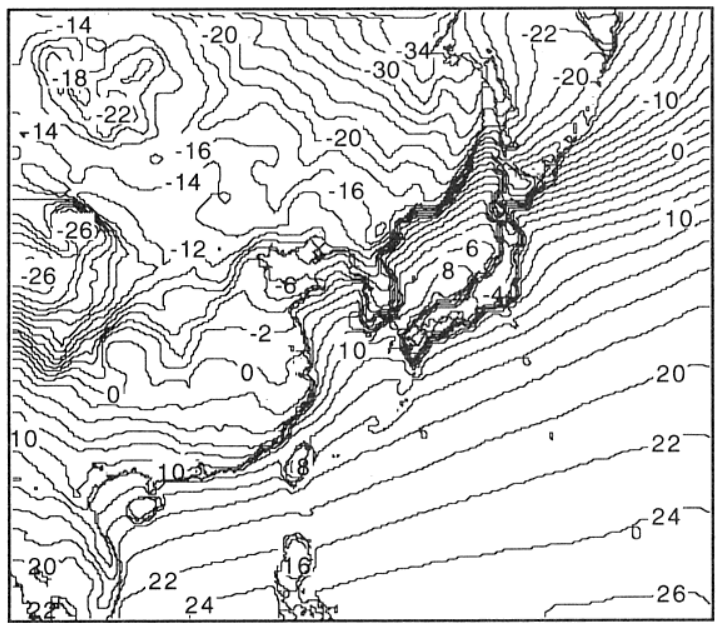

b) Surface Temperature: Jan. (CSM: 1CO2)

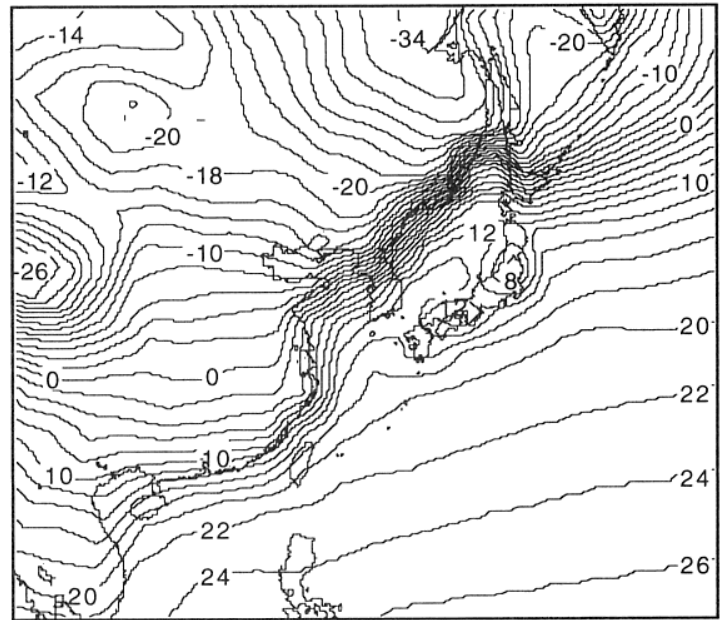

d) Surface Air Temp.: Jan. (RegCM-Obs.)

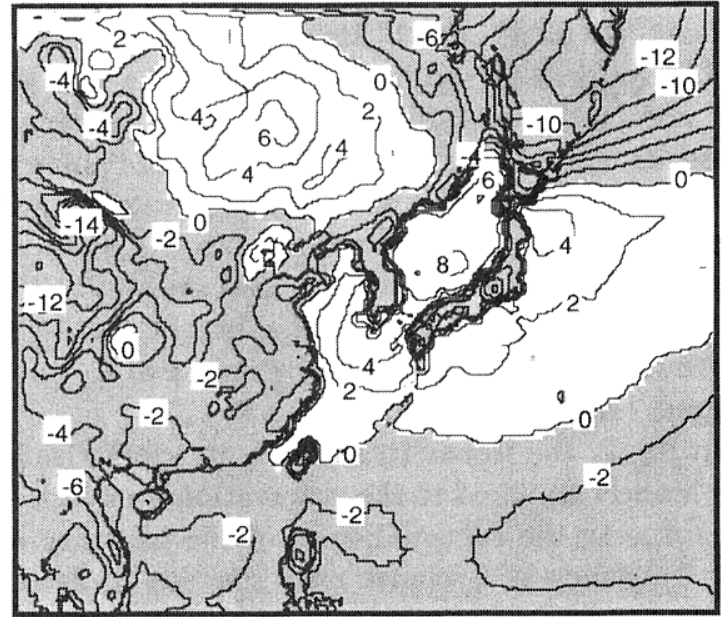

Fig. 3. a) Observed surface air temperature (NCAR data set; 1966-1995), b) 10-year mean surface temperature simulated by the CSM and c) 10-year mean surface air temperature simulated by the RegCM in January for $1 \mathrm{CO}_{2}$ climate. d) Temperature bias in the RegCM. The areas with negative bias are hatched. Units are ${ }^{\circ} \mathrm{C}$. Observed and CSM data are interpolated into the RegCM grid.

Japan), Hokuriku (Japan Sea side), Kanto (Pacific side) and Kyushu (southern Japan) (See Fig. 1c). Surface air temperature is corrected for the model topographic height. The bias in the surface air temperature is small (within about $1{ }^{\circ} \mathrm{C}$ ), except that of Hokkaido (Table 1), where the notable cold bias exists because of the overestimation of the sea ice simulated in the CSM. It is confirmed that the large cold temperature bias exceeding $5{ }^{\circ} \mathrm{C}$ at Wakkanai in Hokkaido is limited in the thin layer below $850 \mathrm{hPa}$ and larger near the surface, which supports the inference for the cause of the cold bias.

In order to clarify the cause of the biases in the surface air temperature (daily mean data), the biases of the daily maximum and minimum air temperature are also investigated at the observation stations in the four districts (Fig. 4a). In Hokkaido, the cold biases are notable both in the maximum and minimum air temperature. However, the biases are larger in the minimum air temperature, which indicates that the surface air temperature on the stations near the coastlines is simulated as 

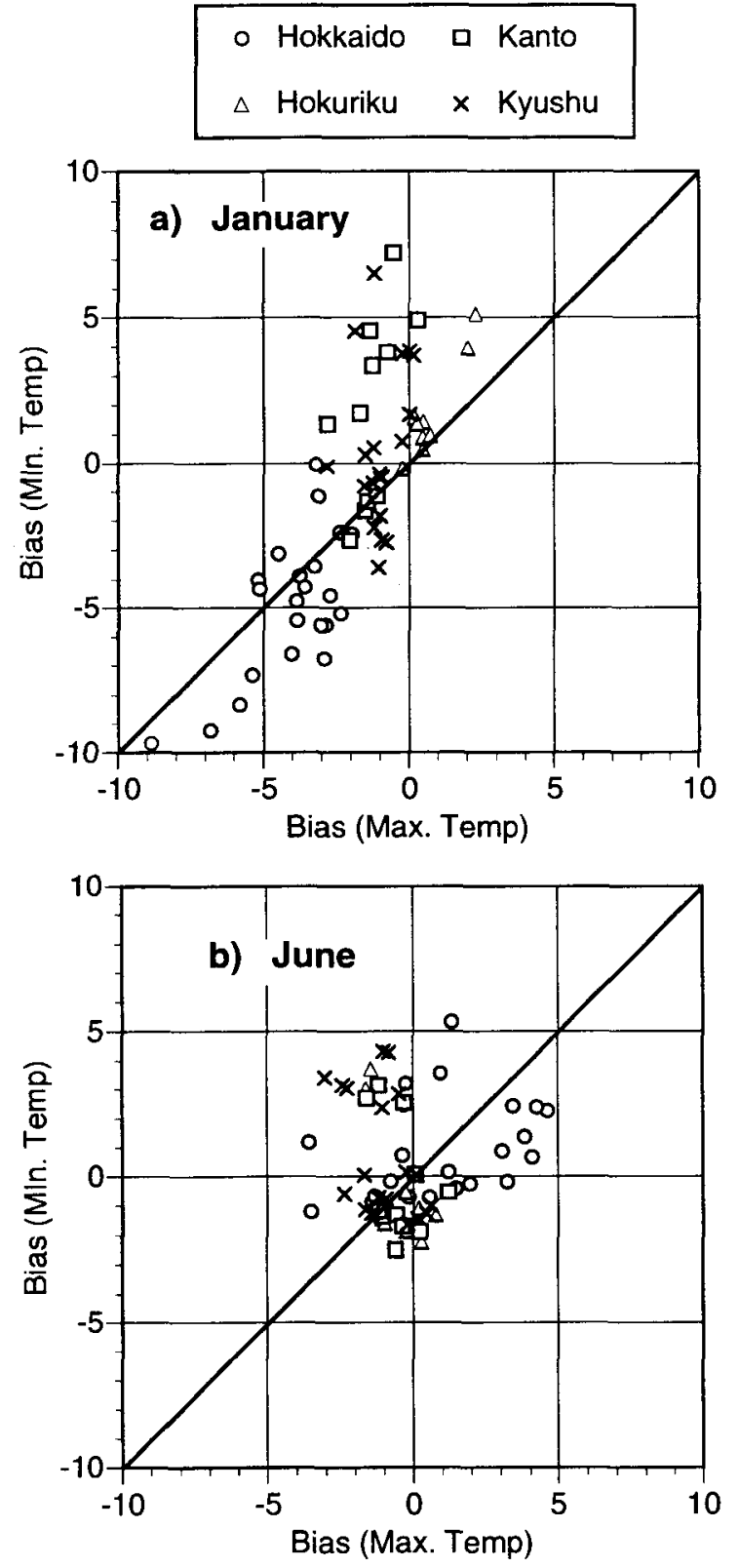

Fig. 4. Comparison of the 10-year mean biases in daily maximum and minimum air temperature simulated by the RegCM at the observation stations in the Japanese four districts. a) January, b) June.

those in the inland area because of the overprediction of the sea ice area. Both in Kanto and Kyushu, the simulated maximum air temperature has negative bias at most observation stations while the minimum air temperature has no tendency. The cold biases in the maximum air temperature are partly due to the deficit in the duration of sunshine, because the RegCM also overpredicts the weak precipitation phenomena (See Section 3.1.c). For the minimum air temperature, both the positive and negative biases are found, except in Hokkaido. It was confirmed that most of the stations with positive bias are facing the ocean, which means that these biases are controlled by the SST bias simulated by the CSM. The other cause of the negative biases in the maximum and minimum air temperature is the urban effect in the observed data reported for these cities (Kato 1996).

\section{c. Precipitation}

In Fig. 5, the 10-year mean precipitation in January simulated by the RegCM is compared to those of the CSM and the observed data set (GPCP: 1987-1996). Both the RegCM and the CSM reproduced well the precipitation area over the ocean east of Japan, which is caused by developed cyclones passing through that area. The total amount of the precipitation is larger in the RegCM than the observed data. The typical precipitation phenomena which occurred on the northwestern side of Japan (Japan Sea side) during the winter monsoon are reproduced clearly in the RegCM and weakly in the CSM although they do not appear in the observed data with the resolution of $2.5^{\circ} \times 2.5^{\circ}$. One example of the precipitation contrast between Kanazawa (Hokuriku) and Tokyo (Kanto), simulated by the RegCM and the CSM, is shown in Fig. 6. From the weather map, it was confirmed that the winter monsoon appeared during 4th to 6 th and 11 th to 13th January of this simulated year. During the days, the precipitation contrasts are clearly simulated by the RegCM while the differences are obscure in the CSM. The vertical distribution patterns of daily mean wind speed and wind direction for the monsoon peak days at Wajima (Hokuriku district) are shown in Fig. 7. The vertical wind shear is found in the lower troposphere on both days which indicates that the model reproduced the precipitation on the northwestern side of Japan under the monsoon wind from the continent.

In Table 1 , the simulated regional precipitation in January is compared with the observed data compiled at JMA because the typical precipitation phenomena on the northwestern side of Japan are not reproduced in Fig. 5a. Although some biases are found, the precipitation contrast between the Hokuriku and Kanto district is well simulated. 
a) Precipitation: Jan. (Observation: 1987-1996)

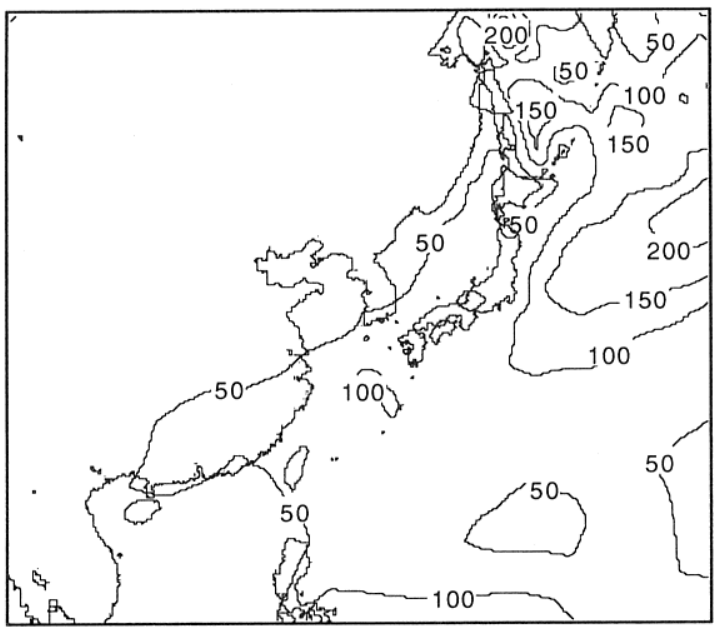

c) Precipitation: Jan. (RegCM: 1CO2)

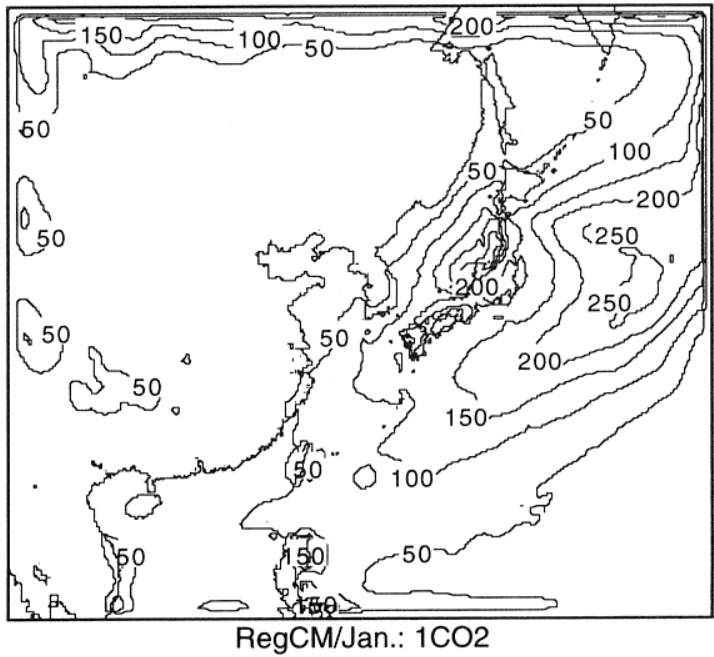

b) Precipitation: Jan. (CSM: 1CO2)

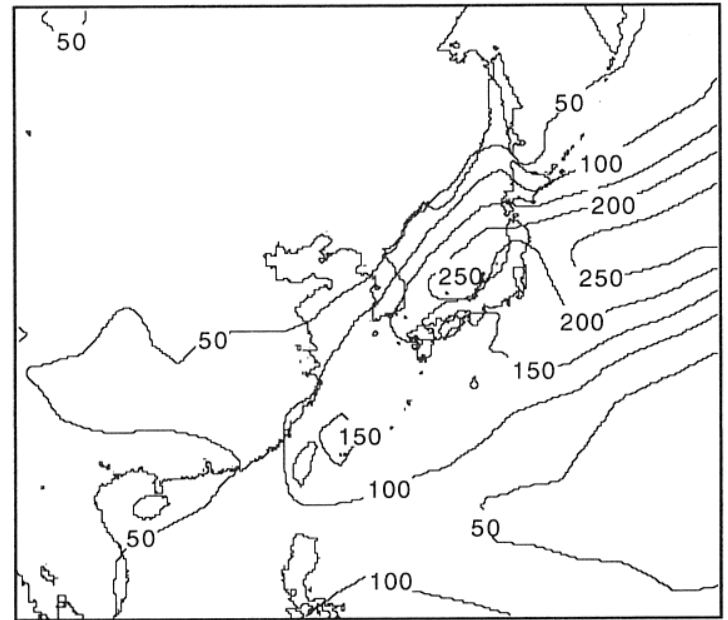

d) Precipitation: Jan. (RegCM-Obs.)

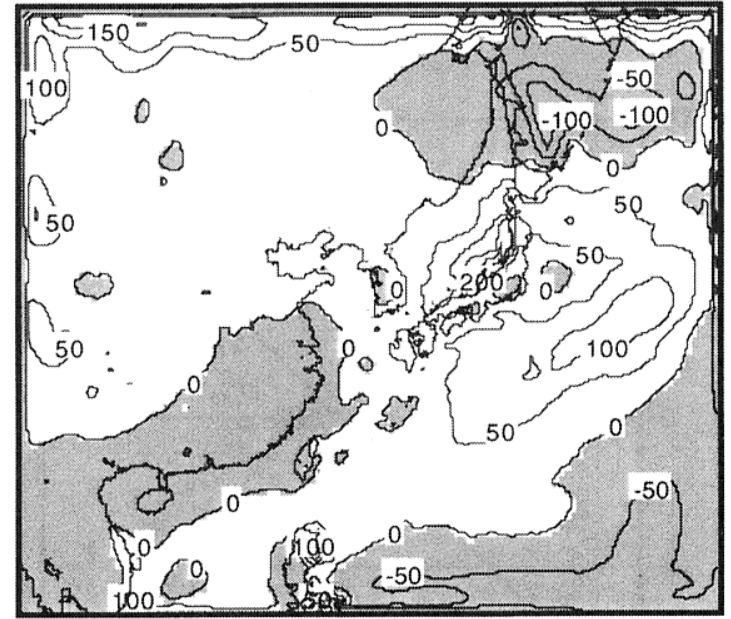

Fig. 5. a) Observed precipitation (GPCP: 1987-1996), and 10-year mean precipitation simulated by b) the CSM and c) the RegCM in January for $1 \mathrm{CO}_{2}$ climate. d) Precipitation bias in the RegCM. The areas with negative bias are hatched. Units are $\mathrm{mm} / \mathrm{month}$.

From the quantitative point of view, the 10-year mean precipitation in the four Japanese districts are well reproduced (within $\pm 50 \%$ ) by the RegCM except that for the Kanto district. The overestimation in the Kanto district is mainly due to the unrealistic topography, exaggerated mountain slope facing the moist southerly wind (Kato et al. 1999). From Fig. 8a, it is clarified that the RegCM has no systematic bias in the total amount of precipitation in January over Japan. However, the total number of the 'precipitation days', defined as the days with precipitation exceeding $1 \mathrm{~mm} /$ day, tends to be overestimated. No systematic tendency is found for the days with larger precipitation exceeding 10 $\mathrm{mm}$ /day. As a result, the number of days with weak precipitation is overpredicted in the model which is similar to the old version of the RegCM (Kato et al. 1999).

\subsection{Climate in June}

a. Sea level pressure

In Fig. 9, the 10-year mean SLP fields in June 

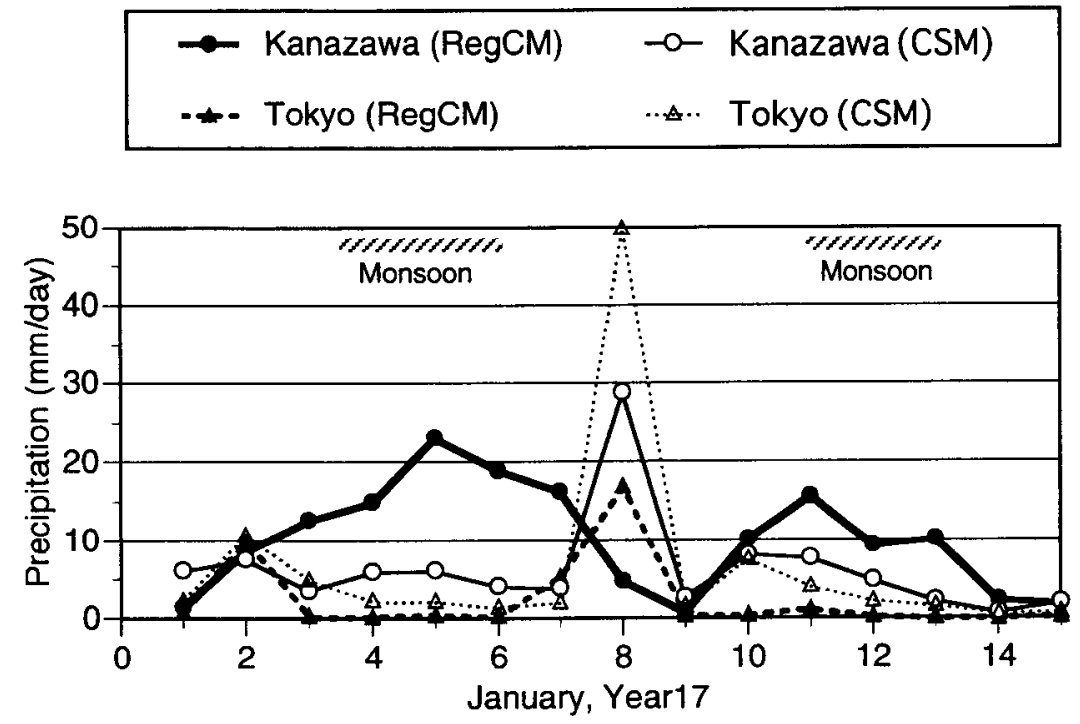

Fig. 6. Time series of the simulated daily precipitation in January of the simulation year Y17 at Kanazawa (Hokuriku; solid line) and Tokyo (Kanto; dotted line). Thick and thin lines correspond to those of the RegCM and the CSM, respectively.

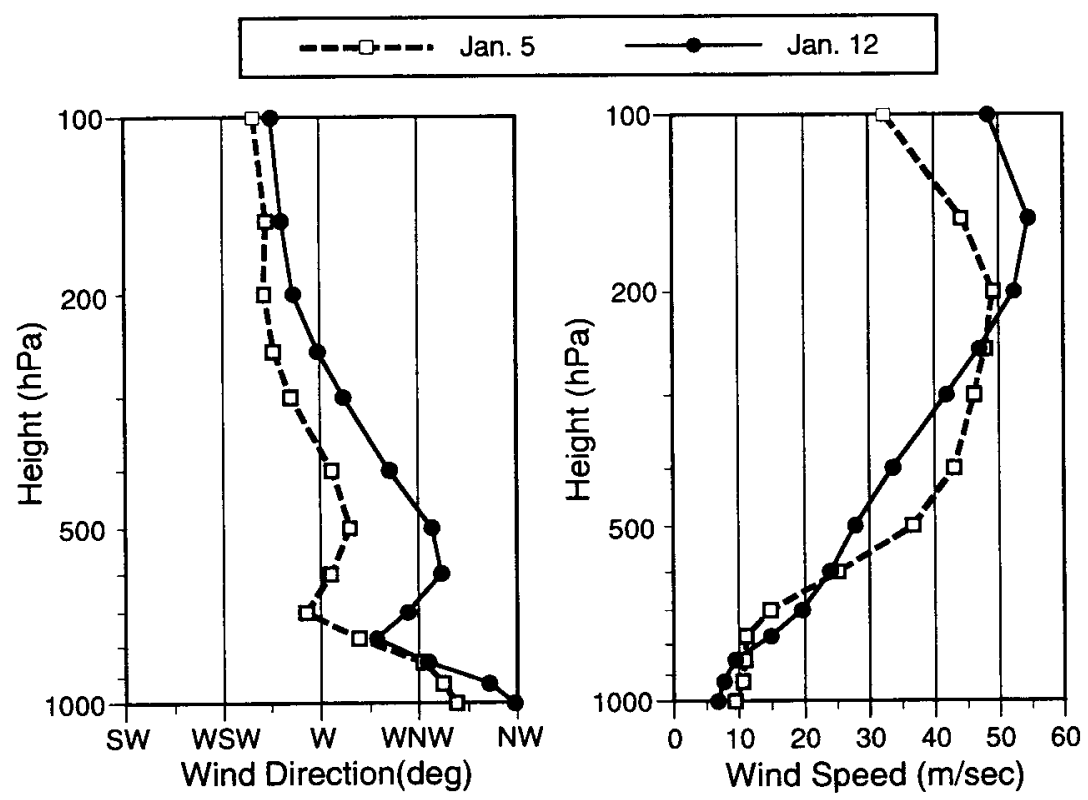

Fig. 7. Vertical distribution of a) wind direction and b) wind speed simulated by the RegCM at Wajima (Hokuriku) on the typical winter monsoon days in January for the simulation year Y17. 
Table 1. Observed (30-year mean) and simulated (10-year mean for $1 \mathrm{CO}_{2}$ by RegCM) monthly mean surface air temperature and the precipitation and their biases (difference between simulated and observed) in January averaged for four districts in Japan. Units are ${ }^{\circ} \mathrm{C}$ (Temp.) and \% (Precipitation), respectively. Simulated temperature is corrected by the topographic height difference.

\begin{tabular}{|c|ccc|ccc|}
\hline & \multicolumn{3}{|c|}{ Temperature } & \multicolumn{3}{c|}{ Precipitation } \\
\cline { 2 - 7 } & Obs. & RegCM & Bias & Obs. & RegCM & Bias (\%) \\
\hline Hokkaido(22points) & -5.2 & -10.2 & -5.0 & 83 & 77 & $-6(-7 \%)$ \\
Hokuriku (9 points) & +2.6 & +3.7 & +1.1 & 273 & 217 & $-56(-20 \%)$ \\
Kanto (11 points) & +4.1 & +4.0 & -0.1 & 49 & 86 & $+37(+75 \%)$ \\
Kyushu (20 points) & +6.1 & +5.7 & -0.4 & 79 & 105 & $+26(+34 \%)$ \\
\hline All Japan (143 points) & +3.2 & +2.3 & -0.9 & 92 & 108 & $+16(+17 \%)$ \\
\hline
\end{tabular}
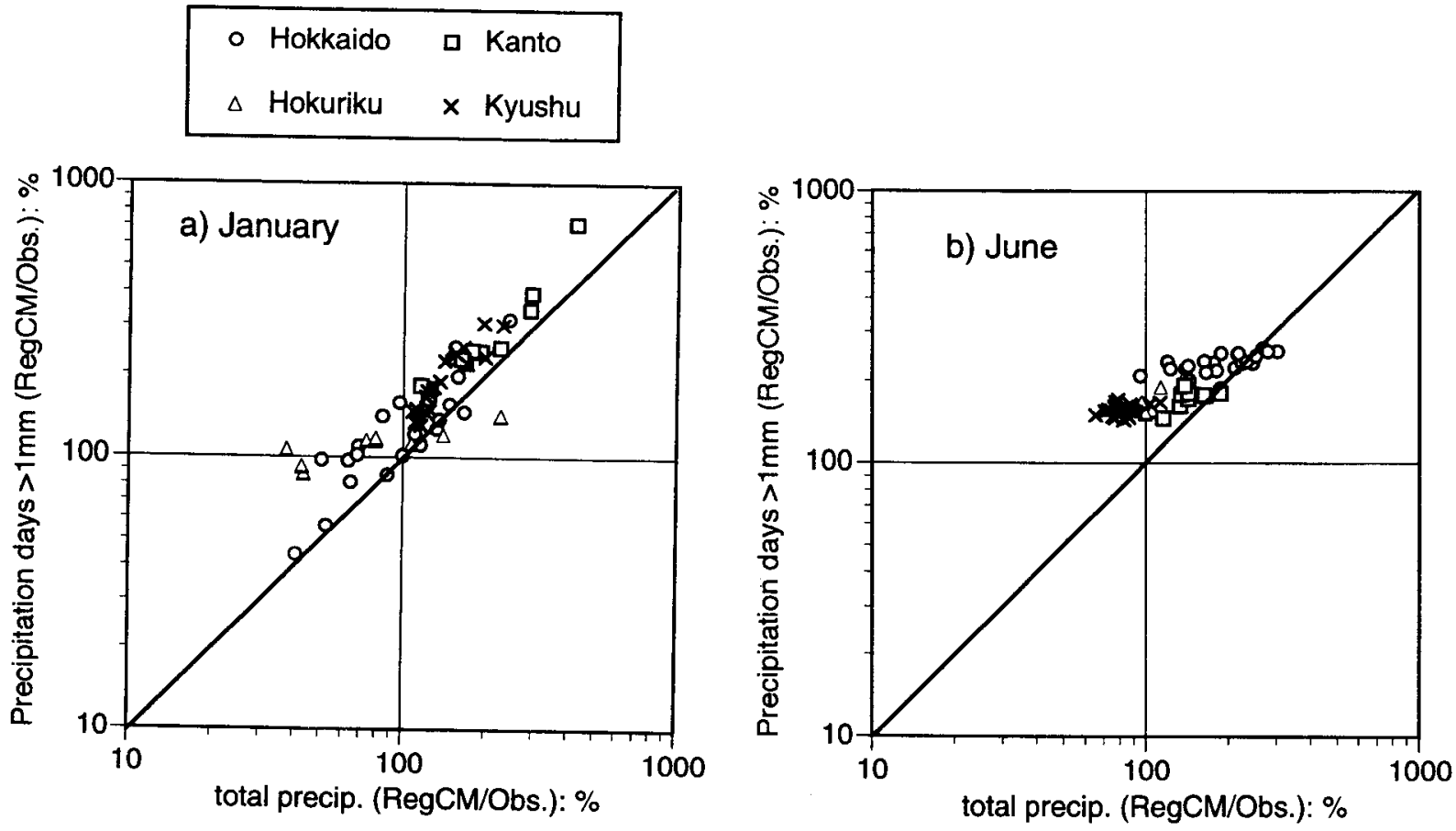

Fig. 8. Comparison of the bias in the monthly precipitation and the total precipitation days (days with precipitation exceeding $1 \mathrm{~mm} /$ day) simulated by the RegCM at the observation stations in the Japanese four districts. Units of the axes are \% to the observed value. a) January, b) June.

simulated by the RegCM and the CSM are compared with that of the 30-year mean observed data. In the models, the North Pacific High (NPH hereafter) tends to develop with the position of its ridge deviating to the north (about 5 to $10^{\circ}$ ) from that of observed data. It was confirmed that the axes of the strong wind on both the $850 \mathrm{hPa}$, and the
$500 \mathrm{hPa}$ surface, shift northward by about $10 \mathrm{de}-$ grees on the 135E line (figures not shown) and the wind speeds are larger by 20 to $30 \%$ than that observed on the line. The easterly wind area south of the NPH extends to the west over the continent in the models, which contributes the precipitation bias there (See Section 3.2.c). The low-pressure 
a) Sea Level Pressure: Jun. (Observation: 1961-1990)

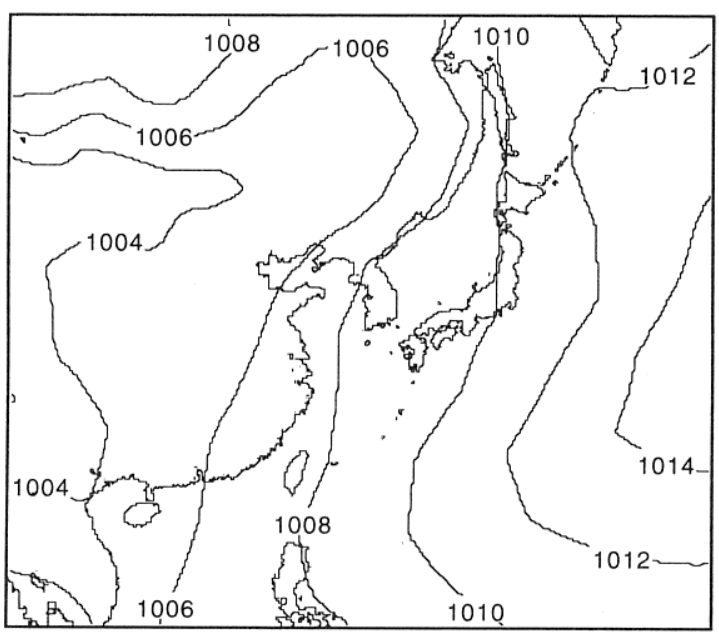

c) Sea Level Pressure: Jun. (RegCM: 1CO2)

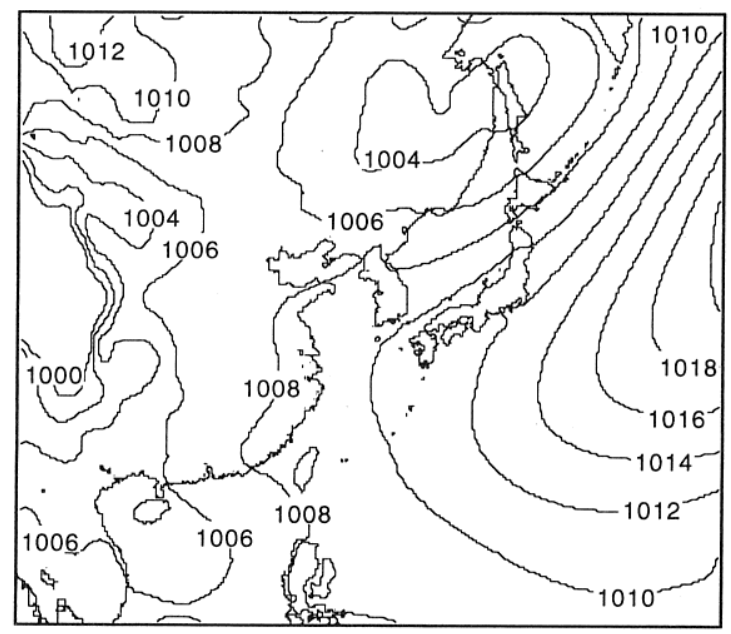

b) Sea Level Pressure: Jun. (CSM: 1CO2)

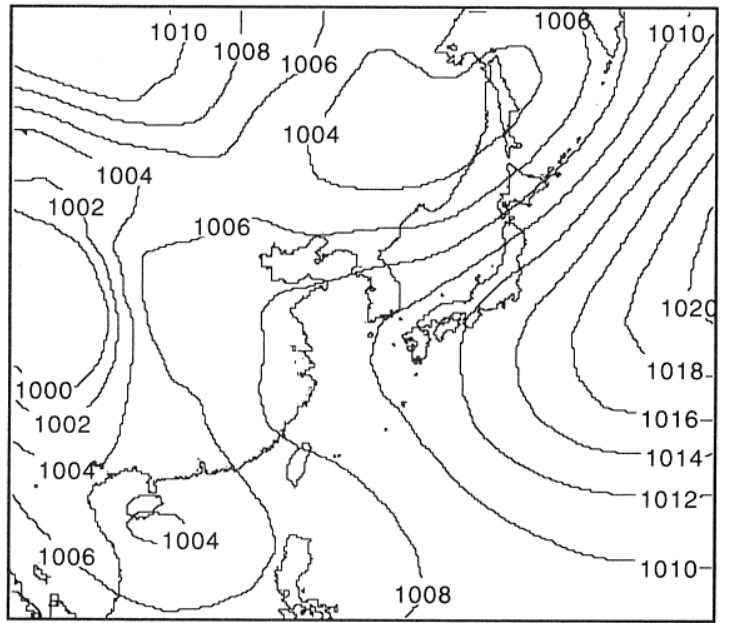

d) Sea Level Pressure: Jun. (RegCM-Obs.)

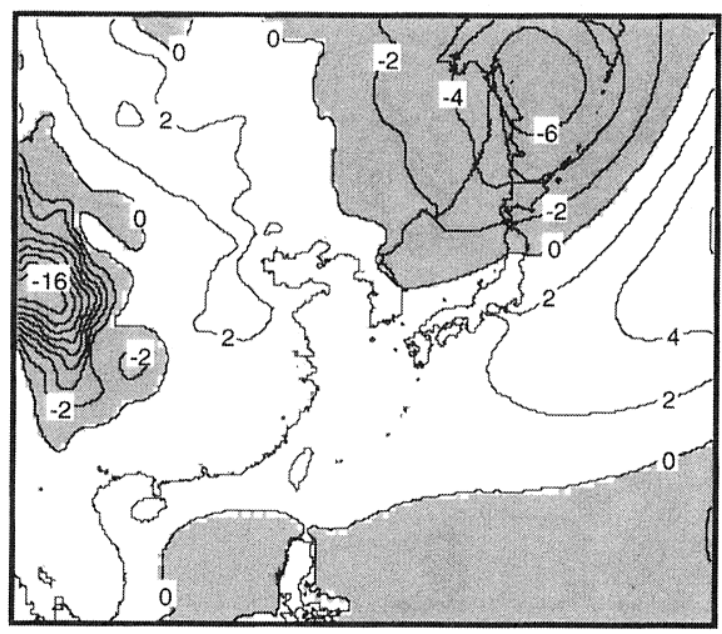

Fig. 9. Same as Fig. 2, but for June.

area over north China extends further to the east and generates negative bias on the Okhotsk Sea in the models. This negative bias is discussed later referring to the temperature bias. Although the models have notable SLP biases in June, these are mainly due to the bias in the CSM since the difference of the SLP fields is small between the RegCM and the CSM.

\section{b. Surface air temperature}

In Fig. 10, the geographic distribution maps of the 10-year mean surface air temperature in June simulated by the RegCM and of the surface temperature simulated by the CSM are shown with 30 - year mean observed surface air temperature. There are large cold biases over the north of Mainland China in the RegCM, which exceed $5{ }^{\circ} \mathrm{C}$ and reach 8 to $9{ }^{\circ} \mathrm{C}$ at maximum. The cold biases in the RegCM are almost the same as those in the surface temperature of the CSM which originated from the overestimation of the area of sea ice in the high latitudes, even in the summer season. In contrast, over the ocean area the temperature biases are smaller, except for those over the Okhotsk Sea. Although the cold biases are larger in the northern region of the Okhotsk Sea and reach about $-4{ }^{\circ} \mathrm{C}$ at maximum, they are smaller in the southern region and the temperature conversely shows a weak positive 
a) Surface Air Temp.: Jun. (Observation: 1966-1995)

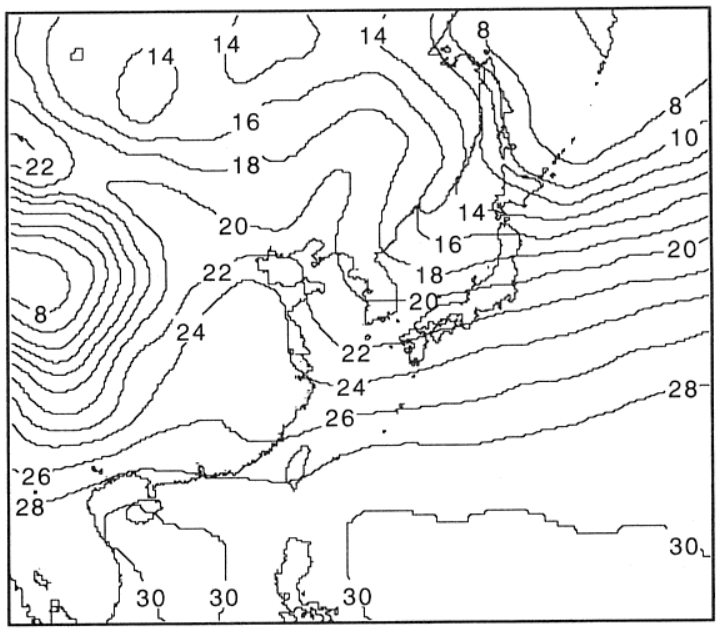

c) Surface Air Temp.: Jun. (RegCM: 1CO2)

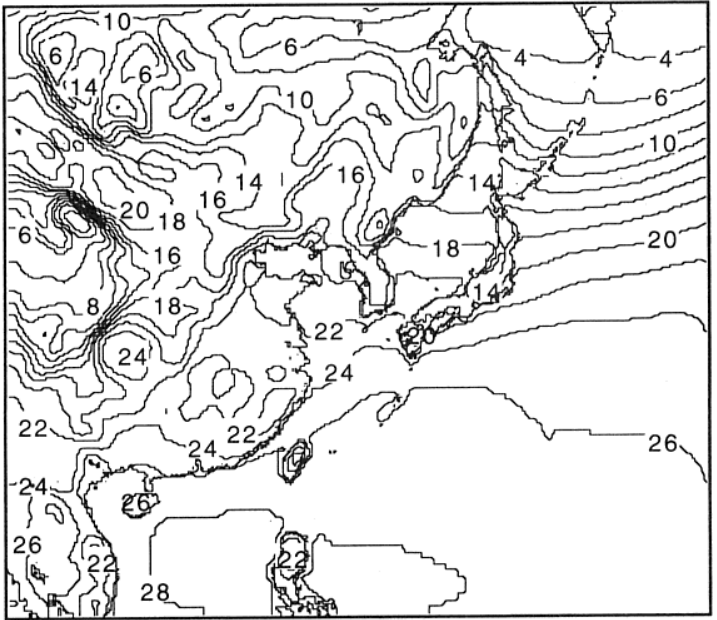

b) Surface Temperature: Jun. (CSM: 1CO2)

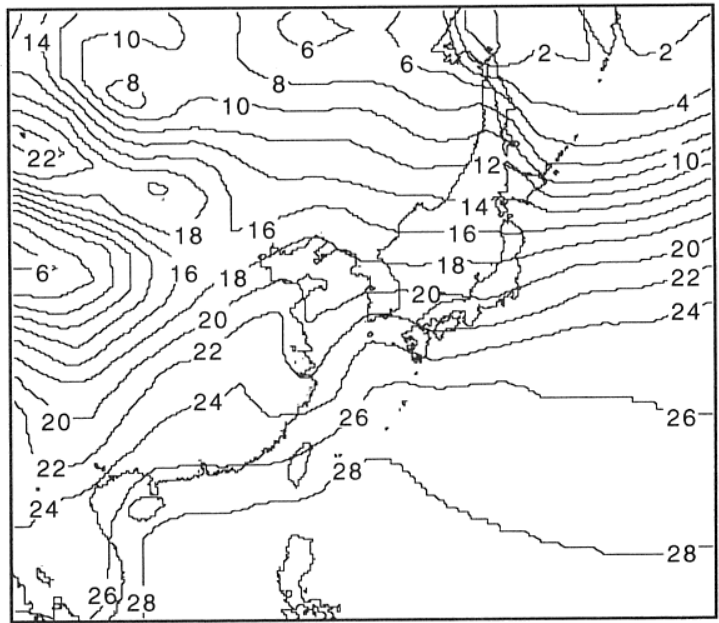

d) Surface Air Temp.: Jun. (RegCM-Obs.)

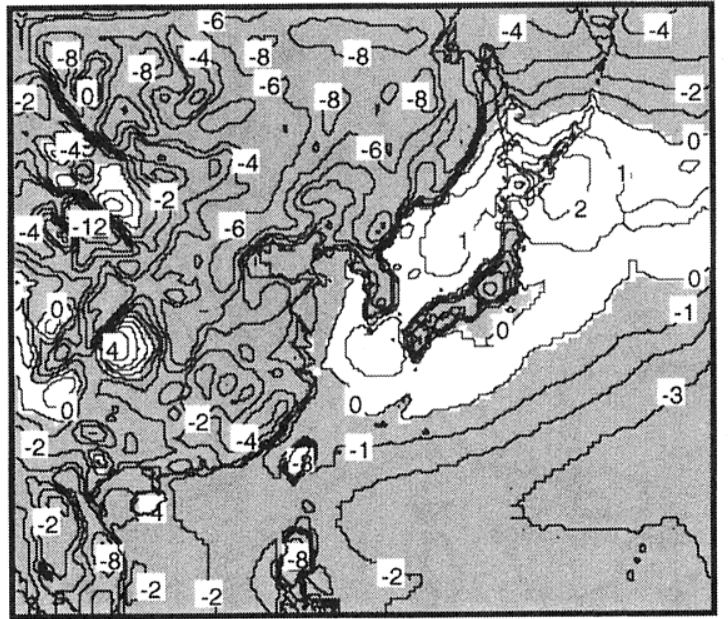

Fig. 10. Same as Fig. 3, but for June.

bias south of the Kuril Islands. A detailed examination of twice-daily weather maps reveals that some cyclones tend to develop over the Okhotsk Sea unrealistically (maximum intensity below 990 $\mathrm{hPa}$ ) in the models. They mainly generate over the northeast of Mainland China in the models, which is far east of the observed generation area, and develop over the Okhotsk Sea. The reason for the discrepancy in the generation area appears to be the negative surface temperature bias in the inner continent, which prevents the generation of cyclones. Cyclones might develop over the comparatively warmer Okhotsk Sea in the CSM (and also in the RegCM) through the heat energy supply. The cold biases near the Philippines in the RegCM are mainly due to those in the CSM. Although they are only 2 to $3{ }^{\circ} \mathrm{C}$, their influence may not be small because the convective activities on the ocean area are one of the important keys to the climate features in the East Asia region (Nitta 1986).

In June, the biases of the 10-year mean surface air temperature of the RegCM in all four districts in Japan are small, i.e., within $\pm 1{ }^{\circ} \mathrm{C}$ (Table 2). In contrast to the result of January, both the positive and negative biases are found in the maximum air temperature in Hokkaido (Fig. 4b). The positive biases are limited to the stations facing the Pacific Ocean. The positive biases of the minimum 
Table 2. Same as Table 1, but for June.

\begin{tabular}{|c|ccc|ccc|}
\hline & \multicolumn{3}{|c|}{ Temperature } & \multicolumn{3}{c|}{ Precipitation } \\
\cline { 2 - 7 } & Obs. & RegCM & Bias & Obs. & RegCM & Bias (\%) \\
\hline \hline Hokkaido(22points) & +13.8 & +14.7 & +0.9 & 88 & 157 & $+69(+79 \%)$ \\
Hokuriku (9 points) & +20.3 & +19.7 & -0.6 & 174 & 187 & $+13(+7 \%)$ \\
Kanto (11 points) & +20.5 & +20.3 & -0.2 & 185 & 268 & $+83(+45 \%)$ \\
Kyushu (20 points) & +22.2 & +22.1 & -0.1 & 345 & 284 & $-61(-18 \%)$ \\
\hline All Japan (143 points) & +20.0 & +19.8 & -0.2 & 211 & 239 & $+28(+13 \%)$ \\
\hline
\end{tabular}

a) Precipitation: Jun. (Observation: 1987-1996)

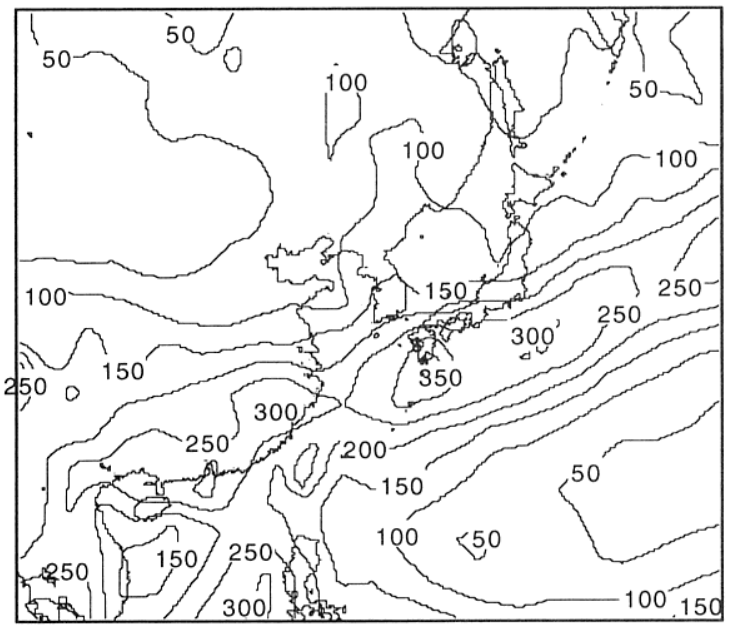

c) Precipitation: Jun. (RegCM: 1CO2)

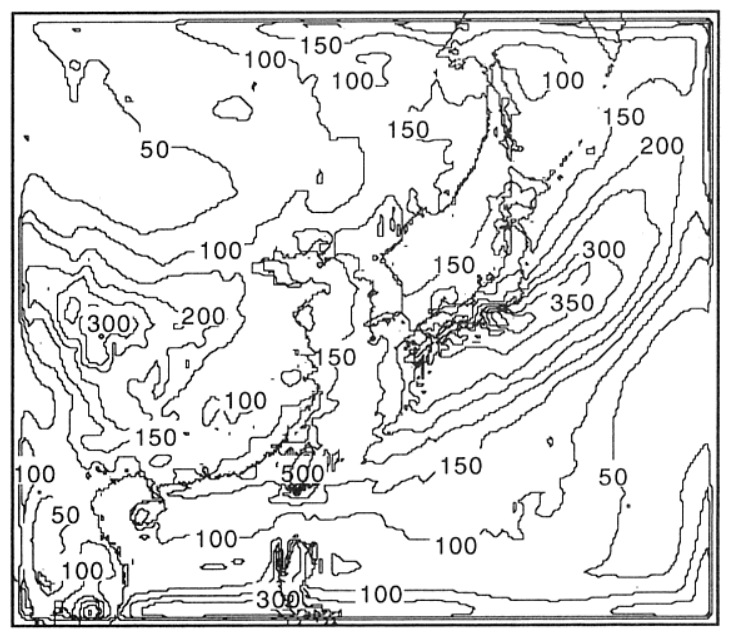

b) Precipitation: Jun. (CSM: 1CO2)

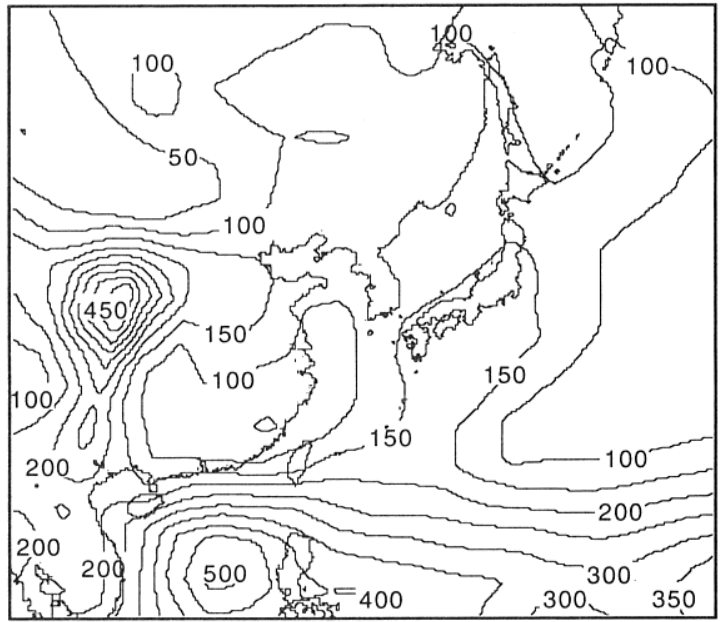

d) Precipitation: Jun. (RegCM-Obs.)

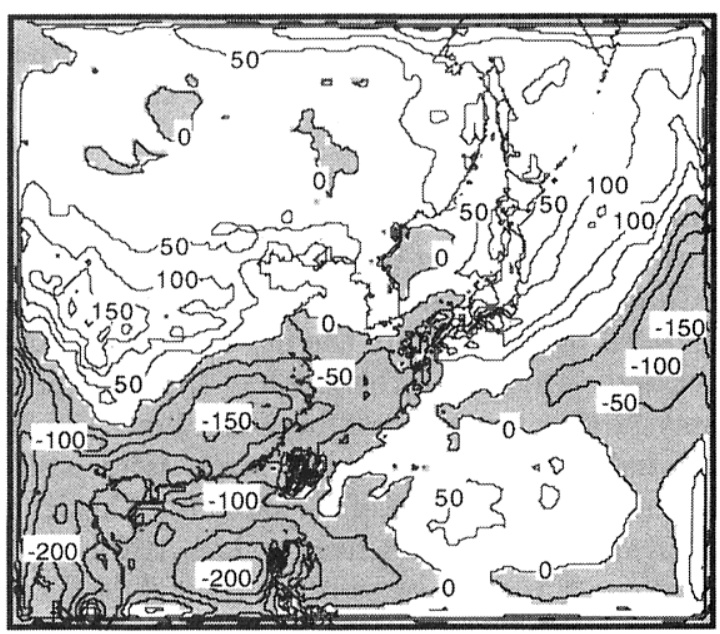

Fig. 11. Same as Fig. 5, but for June. 
air temperature in the Kanto and Kyushu district are found at the stations facing the Pacific Ocean and the Sea of Japan. These results indicate that the bias of the surface air temperature is mainly controlled by the SST bias in the CSM.

\section{c. Precipitation}

In Fig. 11, the 10-year mean precipitation in June simulated by the RegCM is compared to those of the CSM and the observed data set. The precipitation band is reproduced well by the RegCM in the south of Japan, but reproduced weakly by the CSM. The reason for this discrepancy is mainly due to the difference in the precipitation phenomena near the southern boundary of the domain between the RegCM and the CSM. In the CSM, the precipitation occurs near the Philippines caused by the moisture transported there, and little moisture is carried toward Japan. However, in the RegCM simulation, precipitation does not occur in the southern region because of the performance of the precipitation scheme used in the model (i.e., the Kuo type scheme in the RegCM and the ArakawaSchubert type scheme in the CSM) or the restriction by boundary forcing. Furthermore, the difference of the resolution of the models might be a cause of this discrepancy. As a result, moisture is carried into the center of the domain and contributes to the generation of the precipitation band. However, the effect of the model resolution and that of the precipitation scheme are not simply distinguished because the latter often depends on the model resolution. For example, Hirakuchi and Giorgi (1995) treat them as a combined effect. This problem should be investigated in the future through the sensitivity studies using the climate models. In both the RegCM and the CSM, the precipitation in mid- and southern China is underestimated. The models do not reproduce moisture transport from the west of the Philippines to southern China. That is, the location of the NPH ridge is deviated to the north in the model (Fig. 9) and the easterly wind along the south of the NPH penetrates further to the west over southern China. This wind system in the model prevents moisture transport from the south of the domain. Then it is concluded that the Bai-u front, which is the typical stationary front from south or central China to Japan, is reproduced incompletely in the RegCM due to the northern shift of the NPH in the CSM, i.e., the precipitation zone is reproduced only over southern Japan.
In June, the bias of the precipitation averaged over Japan is small as well as that in January and the local biases are within $\pm 50 \%$, except Hokkaido (Table 2). The overestimation in Hokkaido seems to be due to the unrealistically developed cyclones in the northern region of the domain mentioned before. This inference is supported by the fact that the stations at which the RegCM notably overpredict the total precipitation and the precipitation days in Fig. $8 \mathrm{~b}$ (and also days with precipitation exceeding $10 \mathrm{~mm} /$ day) are located along the Japan Sea side. The positive bias in the Kanto district is common with that in January, except it is greater in the total amount in June because of the increased moist southerly wind. On the other hand, negative precipitation biases are found in Kyushu. This underestimation is explained by the fact that the precipitation band is not well reproduced from southern China to the East China Sea. However, in Fig. $8 \mathrm{~b}$, the total number of the precipitation

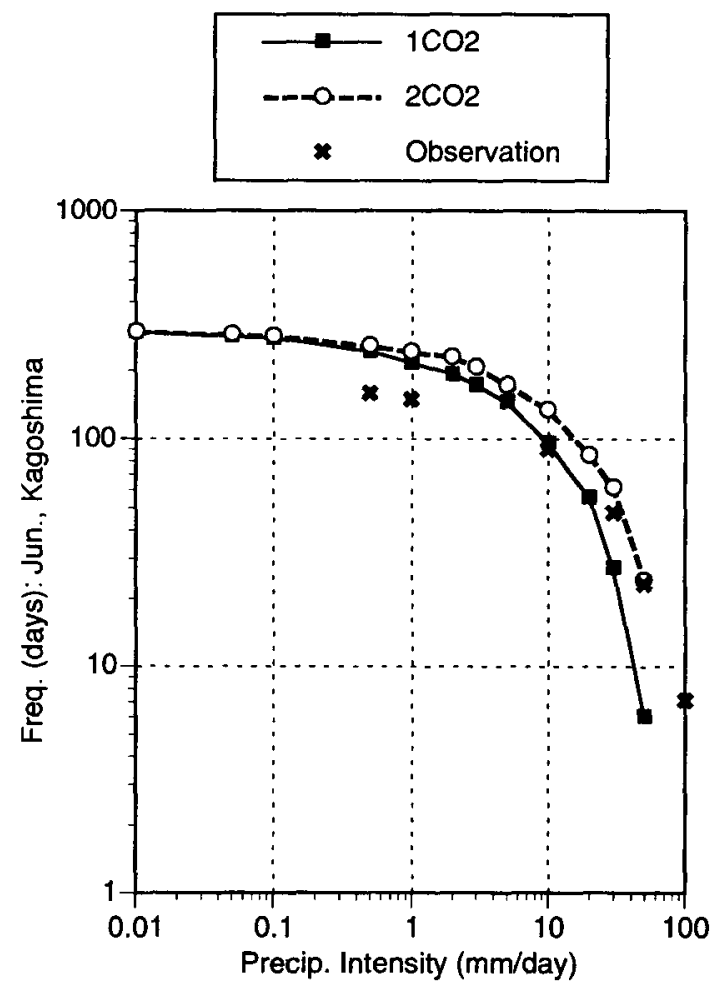

Fig. 12. Change of the accumulated frequency distribution of the daily precipitation in June from $1 \mathrm{CO}_{2}$ to $2 \mathrm{CO}_{2}$ climate simulated at Kagoshima (Kyushu). Observed values (30-year mean: 1961-1990) are also indicated by the crosses in the figure. 
a) Sea Level Pressure: Jan. (RegCM: 2CO2-1CO2)

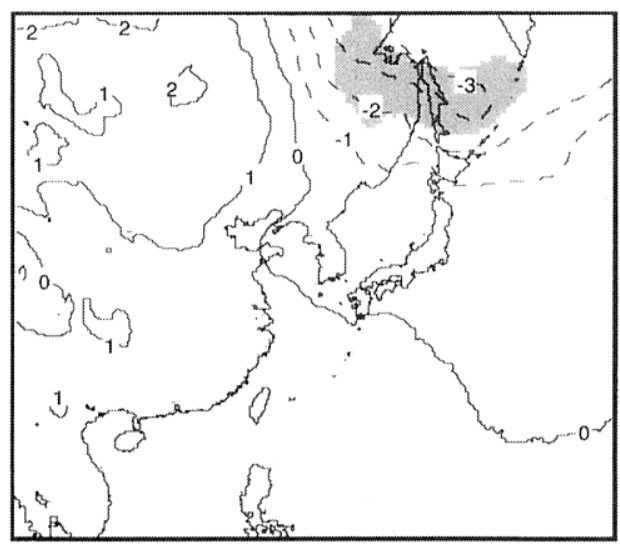

c) Surface Air Temp.: Jan. (RegCM: 2CO2-1CO2)

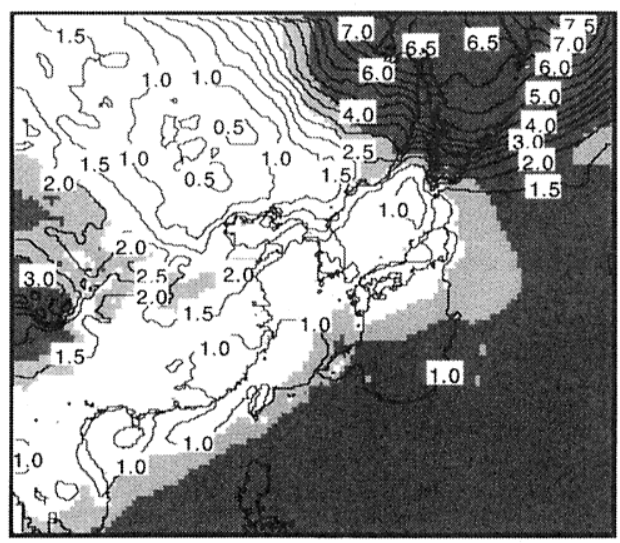

e) Precipitation: Jan. (RegCM: 2CO2-1CO2)

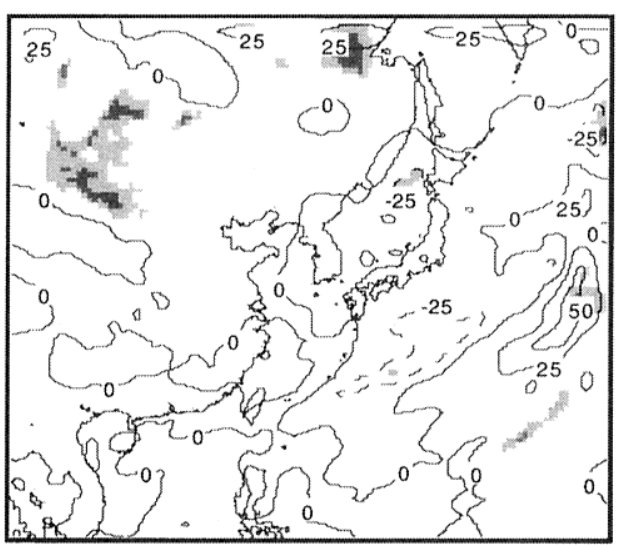

b) Sea Level Pressure: Jan. (CSM: 2CO2-1CO2)

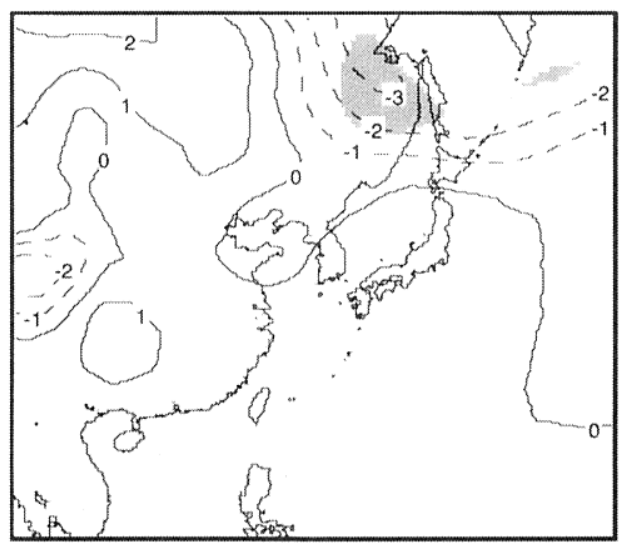

d) Surface Temp.: Jan. (CSM: 2CO2-1CO2)

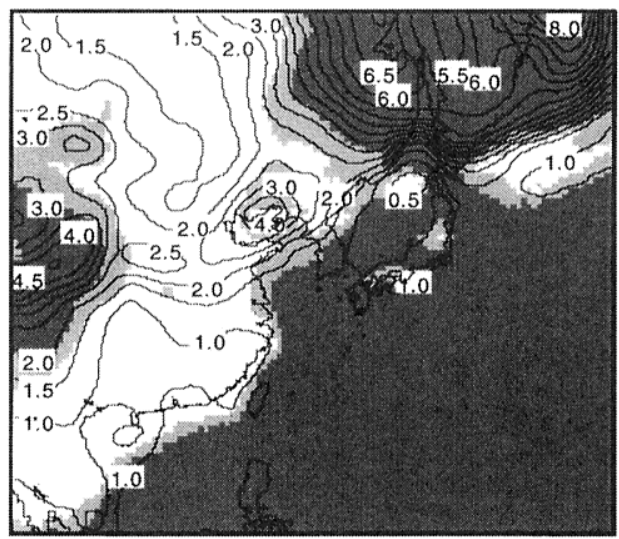

f) Precipitation: Jan. (CSM: 2CO2-1CO2)

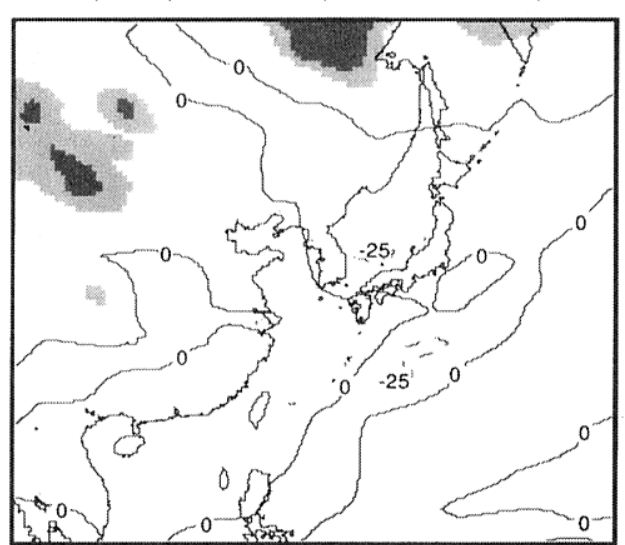

Fig. 13. Change of the 10-year mean a), b) sea level pressure, c), d) temperature and e), f) precipitation in January from $1 \mathrm{CO}_{2}$ to $2 \mathrm{CO}_{2}$ climate simulated by the RegCM (left figures) and the CSM (right figures). Contours are drawn every $1 \mathrm{hPa}$ (negative value by dotted line) for a) and b), every $0.5^{\circ} \mathrm{C}$ for c) and d), and every $25 \mathrm{~mm} /$ month (negative value by dotted line) for e) and f). The areas where the changes are statistically significant at the $1 \%$ (thick) and $5 \%$ level (thin) are hatched. 
a) Sea Level Pressure: Jun. (RegCM: 2CO2-1CO2)

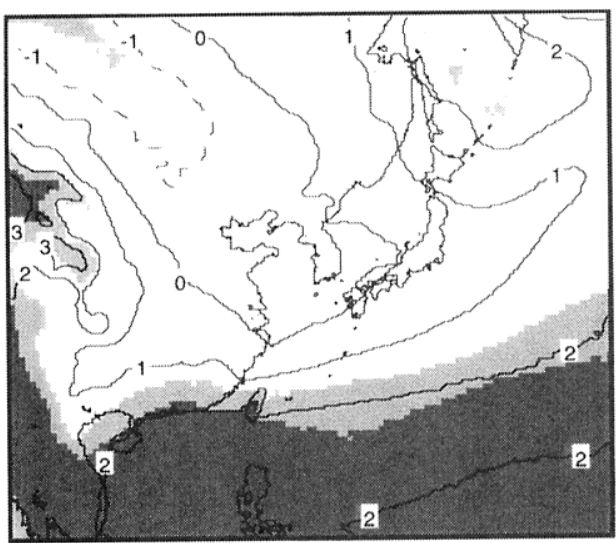

c) Surface Air Temp. Jun. (RegCM: 2CO2-1CO2)

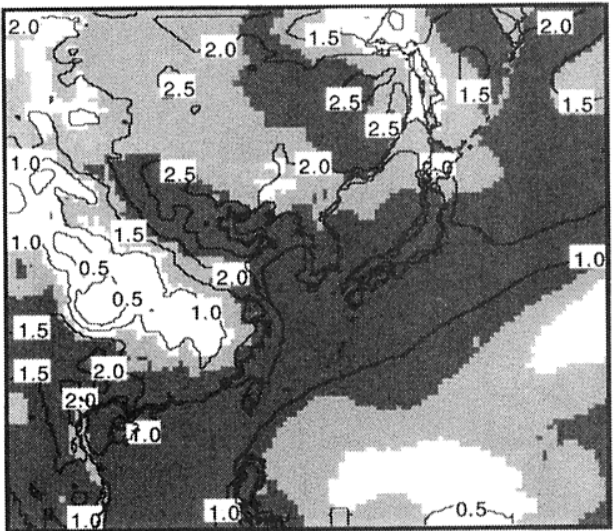

e) Precipitation: Jun. (RegCM: 2CO2-1CO2)

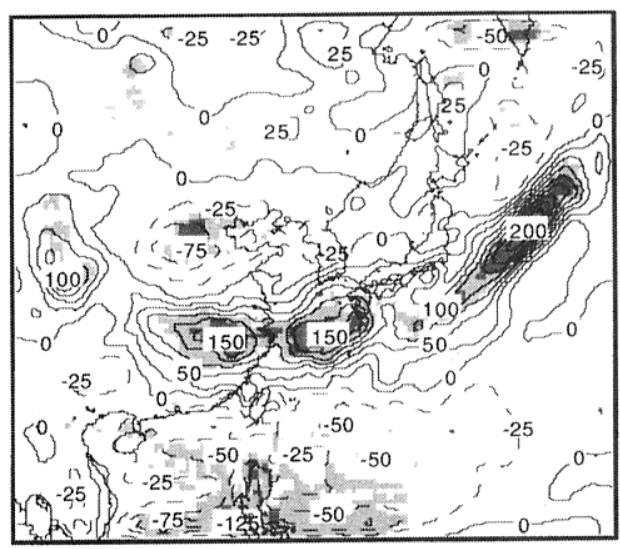

b) Sea Level Pressure: Jun. (CSM: 2CO2-1CO2)

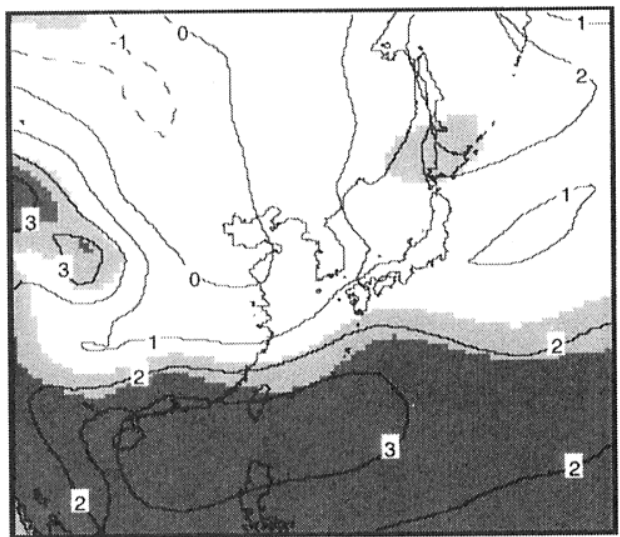

d) Surface Temp.: Jun. (CSM: 2CO2-1CO2)

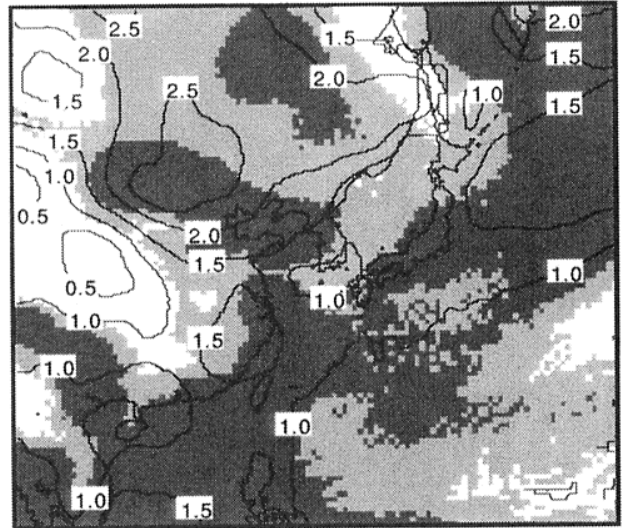

f) Precipitation: Jun. (CSM: 2CO2-1CO2)

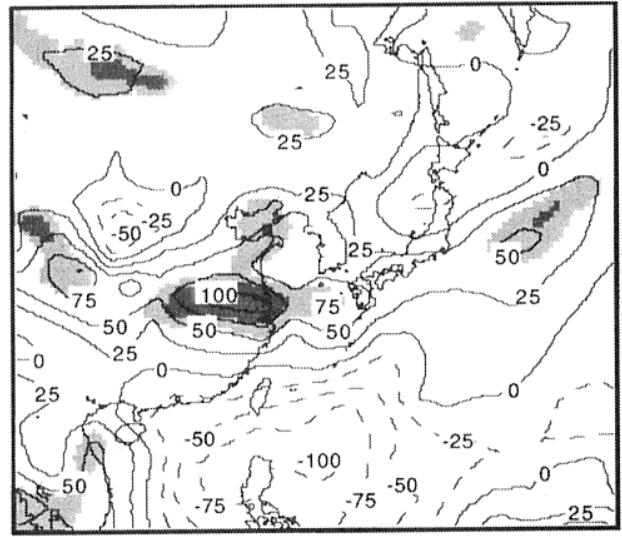

Fig. 14. Same as Fig. 13, but for June. 
days is overestimated (also for the days with 10 $\mathrm{mm} /$ day) at all stations in Kyushu. This indicates that the model does not reproduce much stronger precipitation caused by the Bai-u front there. An example at Kagoshima is shown in Fig. 12. As in the case of January, the frequency of weak precipitation tends to be overestimated at all stations in Japan, and this feature is more conspicuous in June (Fig. 8b).

\section{Discussion of simulated climate change features}

\subsection{East Asia region}

As mentioned in Section 1, these climate change simulations are not intended to provide actual predictions of climate change but to clarify the performance and the problems of this nesting method in the prediction of regional climate change in East Asia through the comparison of the response of the RegCM to a climate perturbation (a doubling $\mathrm{CO}_{2}$ ) against that of the driving CSM, or through the analyses of the causes of climate changes.

In Figs. 13 and 14, climate change features from $1 \mathrm{CO}_{2}$ to $2 \mathrm{CO}_{2}$ simulated by the RegCM and the CSM are compared for January and June, respectively. Generally, the large-scale distributions of SLP and temperature in the RegCM bear a resemblance to those of the GCM although the temperature pattern is much more patchy in the RegCM because of the more realistic description of topography. However, for precipitation, the results are different between the RegCM and the CSM for some areas. For example, in June even the signs of the change are different in the northern part of the Korean Peninsula, i.e., precipitation decrease by 30 to $40 \mathrm{~mm}$ in the RegCM but increase by 30 to 40 $\mathrm{mm}$ in the CSM (Fig. 14e, f). This indicates that the data simply interpolated from the global climate model with coarse resolution should not be used. Instead, the RegCM results with high resolution should be used for assessing the impact of climate change in a region of such complex topography as East Asia, when we can reproduce the realistic present climate by the RegCM.

In January, the considerable temperature increase (up to 6 to $7^{\circ} \mathrm{C}$ ) at high latitudes centered on the Okhotsk Sea is simulated in the models and the change is statistically significant at the $1 \%$ level (Fig. 13c, d). Since this temperature change is mainly due to the melting of sea ice, it is a reasonable change from the qualitative point of view. However, quantitatively, it might be overestimated because the CSM overestimated the area of sea ice especially over the east Okhotsk Sea, as mentioned in Section 3. It should be noted that this increase does not exceed the bias found there (see Fig. 3d). Corresponding to this temperature change, the SLP depresses significantly in the northeastern region of the domain. This may be mainly due to the development of the cyclones receiving the increasing heat energy by the melting of sea ice. It was confirmed that the axes of the strong wind at the 850 and $500 \mathrm{hPa}$ surface does not shift on the $135 \mathrm{E}$ line and its maximum wind speed does not change in the CSM (Kadokura et al. 1998).

In this simulation, the increase of the SLP is notable in the south of NPH in June (Fig. 14a, b) and is statistically significant at the $1 \%$ level. However, over Japan where the northern edge of the NPH located, the SLP does not change. The locations of the axes of the strong wind near $40 \mathrm{~N}$ on the $135 \mathrm{E}$ line do not change both at the 850 and $500 \mathrm{hPa}$ surface, although the wind speed decreases by about $10 \%$ at the $500 \mathrm{hPa}$ surface in the CSM (figure not shown). These results indicate that the NPH develops and extends to the south and west as $\mathrm{CO}_{2}$ increase. However, we have some doubt about this result because the present NPH are not reproduced well in the present climate simulations in the CSM.

Although the precipitation pattern changes corresponding to this SLP pattern change, the features are different between RegCM and CSM. In the result of the RegCM, the precipitation increase (by 20 to $30 \%$ ) on and around the precipitation band is statistically significant at the $5 \%$ (partly $1 \%$ ) level on the southeastern side (Pacific side) of Japan (Fig. 14e). In contrast to these results, the increase of precipitation is not clear there in the result of the CSM (Fig. 14f), because the precipitation band is not well reproduced in the model both in the $1 \mathrm{CO}_{2}$ and the $2 \mathrm{CO}_{2}$ climate. Although the large increase (statistically significant at the $5 \%$, partly $1 \%$ ) occurs in mid-China and over the ocean to the west of Japan in both models, this may include error because the precipitation band over the regions is not reproduced well in the $1 \mathrm{CO}_{2}$ climate (Fig. 11b, c). Namely, the increase is almost the same level as the bias. Then, these changes may be spurious due to the bias in the present climate of CSM results.

From these results, it is clarified that the simulated climate change of East Asia by the RegCM is mainly influenced by the bias of the CSM in reproducing the present climate, e.g., sea ice area, 
position and intensity of the anticyclones. Then it should be stressed that it is of utmost importance that the AOGCM information is of good quality. Furthermore, in order to confirm the significance of the results, the simulation period should be as long as possible.

\subsection{In and around Japan}

Temperature and precipitation changes both in January and June in the four Japanese districts are summarized in Table 3. Qualitatively, the RegCM and the CSM simulated the similar increasing tendency in temperature and indicated that the warm- ing is greater in June than in January, except in Hokkaido. Agreement of the model temperature results are also confirmed from the correlation coefficient of monthly mean values of 10 year data both for $1 \mathrm{CO}_{2}$ and $2 \mathrm{CO}_{2}$ (Table 4 ). However, the magnitude of warming of the RegCM is larger in Hokkaido in January and somewhat larger in all the districts in June between the models. These differences are mainly due to the interpolation procedure from the CSM data. When we obtain temperature data at any point in Japan from CSM data, surrounding ocean data are often used in the interpolation. Then the warming simulated over land in

Table 3. a) Temperature and b) precipitation change due to the doubling of $\mathrm{CO}_{2}$ (difference between 10-year means for $1 \mathrm{CO}_{2}$ and $2 \mathrm{CO}_{2}$ ) averaged for four districts in Japan in January and June. Units are ${ }^{\circ} \mathrm{C}$ (Temp.) and \% (Precipitation), respectively.

\begin{tabular}{|c|c|c|c|c|c|c|c|}
\hline & & & Hokkaido & Hokuriku & Kanto & Kyushu & All Japan \\
\hline \multirow{2}{*}{ a) Temp. } & Jan. & $\begin{array}{c}\text { RegCM } \\
\text { CSM } \\
\end{array}$ & $\begin{array}{l}+2.9^{\star \star} \\
+1.8^{\star \star} \\
\end{array}$ & $\begin{array}{l}+1.0 \\
+0.9^{\star *} \\
\end{array}$ & $\begin{array}{l}+0.8 \\
+1.0^{* *} \\
\end{array}$ & $\begin{array}{l}+1.0 \\
+1.1^{\text {** }}\end{array}$ & $\begin{array}{l}+1.3^{*} \\
+1.1^{* *}\end{array}$ \\
\hline & Jun. & $\begin{array}{c}\text { RegCM } \\
\text { CSM } \\
\end{array}$ & $\begin{array}{l}+1.9^{* \star} \\
+1.3^{*} \\
\end{array}$ & $\begin{array}{l}+1.7^{\star *} \\
+1.3^{\star *}\end{array}$ & $\begin{array}{l}+1.5^{* *} \\
+1.3^{* *}\end{array}$ & $\begin{array}{l}+1.5^{* *} \\
+1.0^{*}\end{array}$ & $\begin{array}{l}+1.6^{\star \star} \\
+1.2^{\star \star}\end{array}$ \\
\hline \multirow[t]{2}{*}{ b) Precip. } & Jan. & $\begin{array}{c}\text { RegCM } \\
\text { CSM } \\
\end{array}$ & $\begin{array}{r}-9 \\
-15 \\
\end{array}$ & $\begin{array}{l}-3 \\
-8 \\
\end{array}$ & $\begin{array}{l}-12 \\
-4 \\
\end{array}$ & $\begin{array}{r}-4 \\
+6 \\
\end{array}$ & $\begin{array}{l}-7 \\
-4 \\
\end{array}$ \\
\hline & Jun. & $\begin{array}{c}\text { RegCM } \\
\text { CSM }\end{array}$ & $\begin{array}{r}+8 \\
-14 \\
\end{array}$ & $\begin{array}{l}+1 \\
-4\end{array}$ & $\begin{array}{r}+12 \\
+5 \\
\end{array}$ & $\begin{array}{l}+42^{*} \\
+28 \\
\end{array}$ & $\begin{array}{r}+16 \\
+5 \\
\end{array}$ \\
\hline
\end{tabular}

** significant at the $1 \%$ level, * significant at the $5 \%$ level

Table 4. Correlation coefficient of simulated monthly mean values between RegCM and CSM for four districts in Japan in January and June. a) Surface air temperature of RegCM and surface temperature of CSM, b) Precipitation.

\begin{tabular}{|c|c|c|c|c|c|c|c|}
\hline & & & Hokkaido & Hokuriku & Kanto & Kyushu & All Japan \\
\hline \multirow[t]{2}{*}{ a) Temp. } & Jan. & $\begin{array}{l}1 \mathrm{CO} 2 \\
2 \mathrm{CO} 2 \\
\end{array}$ & $\begin{array}{l}0.37 \\
0.82 \text { ** } \\
\end{array}$ & $\begin{array}{l}0.92^{* *} \\
0.93^{* \star}\end{array}$ & $\begin{array}{l}0.92^{* *} \\
0.89^{* *}\end{array}$ & $\begin{array}{l}0.92^{\star *} \\
0.66^{*}\end{array}$ & $\begin{array}{l}0.91^{* *} \\
0.85^{* *}\end{array}$ \\
\hline & Jun. & $\begin{array}{l}1 \mathrm{CO} 2 \\
2 \mathrm{CO} 2 \\
\end{array}$ & $\begin{array}{l}0.91 * * \\
0.69 \text { * }\end{array}$ & $\begin{array}{l}0.79^{\star *} \\
0.78^{* *}\end{array}$ & $\begin{array}{l}0.88^{\text {**}} \\
0.82^{\text {**}}\end{array}$ & $\begin{array}{c}0.52 \\
0.67^{\star}\end{array}$ & $\begin{array}{l}0.82^{* \star} \\
0.72^{*}\end{array}$ \\
\hline \multirow[t]{2}{*}{ b) Precip. } & Jan. & $\begin{array}{r}1 \mathrm{CO} 2 \\
2 \mathrm{CO} 2 \\
\end{array}$ & $\begin{array}{l}0.63^{*} \\
0.84^{\star *}\end{array}$ & $\begin{array}{l}0.76^{* *} \\
0.82^{\star *}\end{array}$ & $\begin{array}{l}0.93^{\star *} \\
0.68^{*} \\
\end{array}$ & $\begin{array}{l}0.64^{*} \\
0.74^{\star *}\end{array}$ & $\begin{array}{l}0.79^{\text {**}} \\
0.78^{\text {** }}\end{array}$ \\
\hline & Jun. & $\begin{array}{l}1 \mathrm{CO} 2 \\
2 \mathrm{CO} 2\end{array}$ & $\begin{array}{l}0.65^{*} \\
0.69 *\end{array}$ & $\begin{array}{l}0.42 \\
-0.06\end{array}$ & $\begin{array}{l}0.40 \\
0.11\end{array}$ & $\begin{array}{l}0.45 \\
0.45\end{array}$ & $\begin{array}{l}0.64^{*} \\
0.27\end{array}$ \\
\hline
\end{tabular}

** Significant at the $1 \%$ level, * significant at the $5 \%$ level 
the RegCM must be different from the interpolated CSM data when the warming is significantly different between over land (or sea ice) and ocean. Another difference between the model results is that the temperature increase in January is statistically significant at the $1 \%$ level only in the CSM results. It is due to the fact that the variance of the data at one mesh in the CSM is smaller because of the larger mesh size.

In Fig. 15a, the changes of the 10-year mean maximum and minimum surface air temperature of RegCM are compared at the observation stations in the four districts in January. The increase of the daily mean surface air temperature in Hokkaido is attributed to that of the daily minimum surface air temperature rather than that of the maximum surface air temperature. The changes are statistically significant at the $5 \%$ level at all the stations in minimum air temperature and at about half of the stations in the maximum air temperature. While in other districts, the increase of the maximum air temperatures is almost the same as that of the minimum air temperature, and both correspond to that of a nearby SST although the changes of the maximum and minimum surface air temperatures are not statistically significant at most of the stations as in the case of the daily mean temperature. Also in June, the increase of the maximum air temperatures is almost the same as that of the minimum air temperature (Fig. 15b), and both are somewhat larger than that of a nearby SST. The increase of both the maximum and minimum air temperatures is statistically significant at the $5 \%$ level at all the stations. These results indicate that the main part of the increase of the surface air temperature in Japan is controlled by the warming of SST surrounding Japan. Then, in the prediction of surface air temperature change in Japan, the simulation of SST change in the global climate model plays an important role. At some stations in Kyushu, the increase of the minimum air temperature exceeds that of the maximum air temperature (Fig. 15b). These stations are located along the western side of Kyushu. This feature may be caused by the suppression of the increase of the maximum air temperature due to the increasing precipitation days, i.e., decreasing of sunshine duration.

Precipitation changes in June simulated by RegCM and CSM are somewhat dissimilar to each other although the changes are small and are not statistically significant (Table 3). These dissimilarities are also confirmed from the fact that the
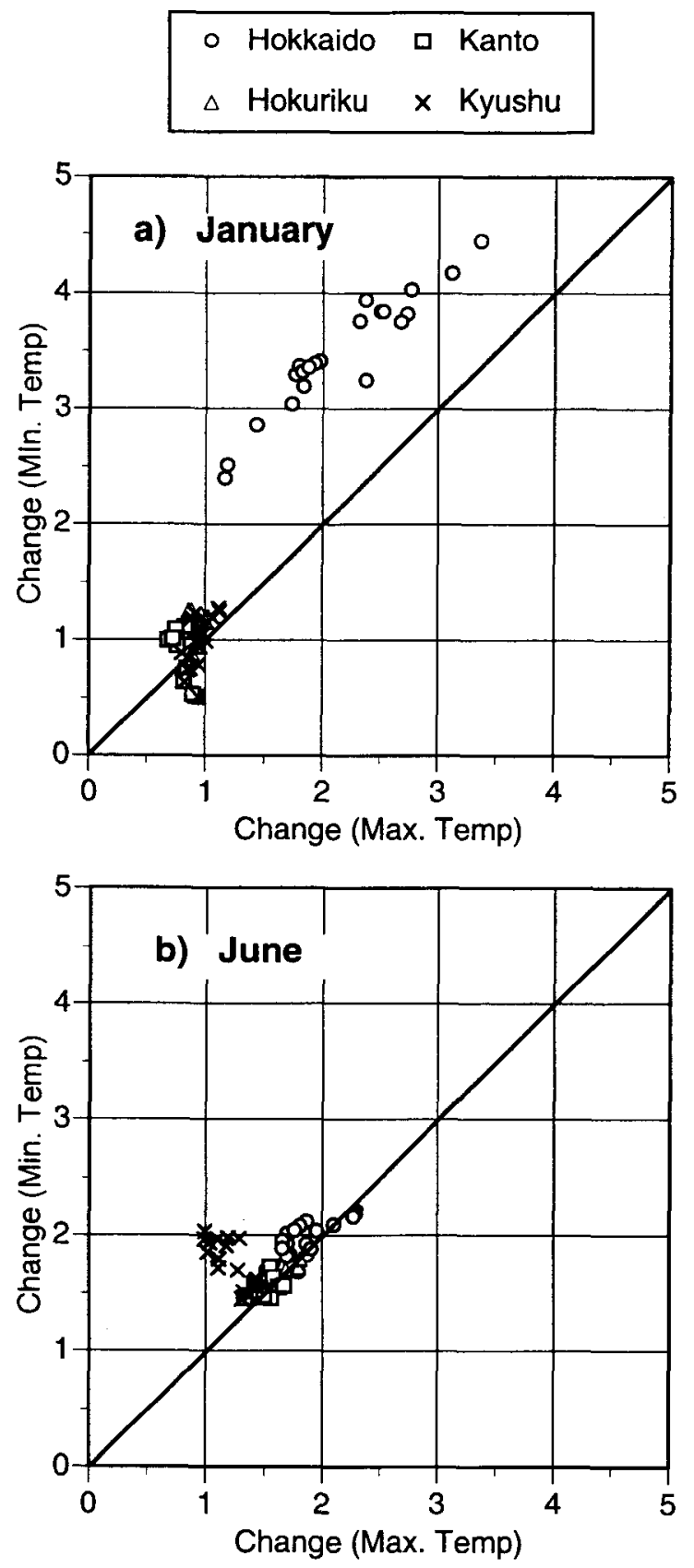

Fig. 15. Comparison of the changes in the 10-year mean daily maximum and minimum air temperature from $1 \mathrm{CO}_{2}$ to $2 \mathrm{CO}_{2}$ climate simulated by the RegCM at the observation stations in the Japanese four districts. a) January, b) June. Units of the axes are ${ }^{\circ} \mathrm{C}$. 
correlation coefficients of the monthly mean precipitation between RegCM and CSM are different between $1 \mathrm{CO}_{2}$ and $2 \mathrm{CO}_{2}$ (Table 4 ) for some districts. The different correlation coefficients between two decades depend on the degree of the incompleteness of precipitation band in the CSM. In case of January, precipitation in and around Japan is mainly controlled by the cyclones passing over there rather than that caused by the winter monsoon both in $1 \mathrm{CO}_{2}$ and $2 \mathrm{CO}_{2}$. Then the correlation coefficients keep significant values.

By using RegCM, more detailed information is obtained in the regional precipitation. In June, precipitation in Kyushu tends to increase as $\mathrm{CO}_{2}$ increases, where the change is statistically significant at the $5 \%$ level. However, in contrast to the notable increase of total precipitation, the number of precipitation days does not change or only slightly increases there (Fig. 16), which means that the average precipitation intensity becomes stronger as $\mathrm{CO}_{2}$ increases. It seems to be due to the intensification of the precipitation band. For all stations in Kyushu, the increasing rate of the total

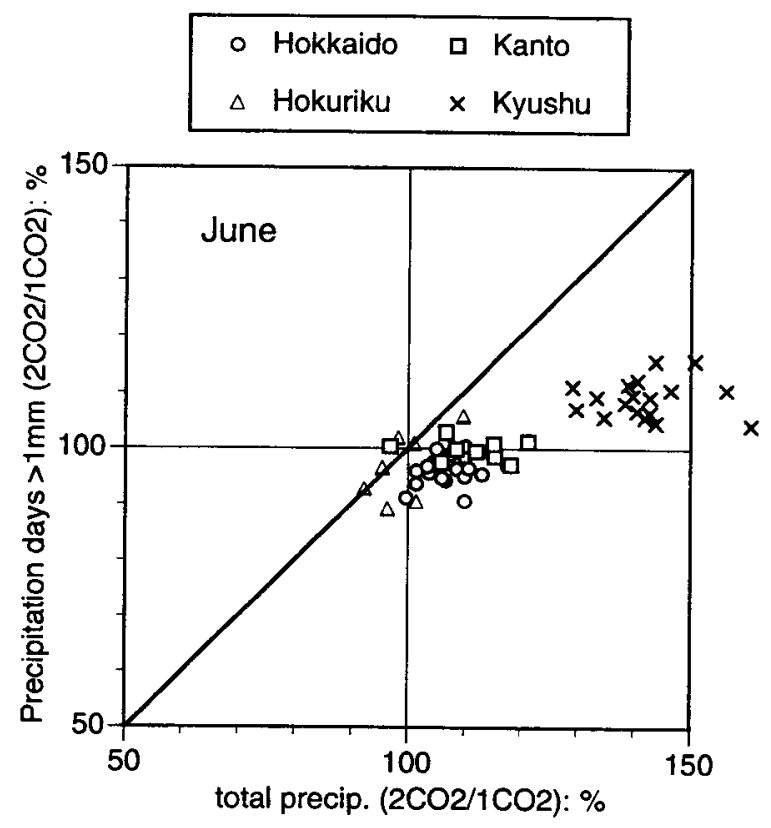

Fig. 16. Comparison of the change of the monthly precipitation and the total precipitation days (days with precipitation exceeding $1 \mathrm{~mm} /$ day) in June from $1 \mathrm{CO}_{2}$ to $2 \mathrm{CO}_{2}$ climate simulated by the RegCM at the observation stations in the Japanese four districts. Units of the axes are $\%$ to the results of $1 \mathrm{CO}_{2}$. number of the days with precipitation exceeding 10 $\mathrm{mm} /$ day is in the range of 116 to $143 \%$, which is larger than that of the precipitation days. One example at Kagoshima is shown in Fig. 12, where the change of the accumulated frequency distribution of the daily precipitation is shown. Same tendency is found in Kanto where the precipitation band is also notable. In this experiment, notable geographical shift of the precipitation band is not observed. However, these results should be investigated again when the Bai-u front is realistically reproduced in the present climate simulation.

\section{Conclusions}

Regional climate in East Asia under $1 \mathrm{CO}_{2}$ and $2 \mathrm{CO}_{2}$ conditions was simulated for continuous $10-$ year periods by the RegCM2.5 developed by NCAR, using the output of a $\mathrm{CO}_{2}$ transient run from NCAR-CSM as lateral and surface boundary conditions. In this study, January and June climates were analyzed. These climate change simulations are not intended to provide actual predictions of climate change, but to clarify the problems of this nesting method in the prediction of regional climate change in East Asia.

The performance of this model system is clarified through the validation of the simulated present climate. The typical precipitation phenomenon which occurs on the northwestern side of Japan during the winter monsoon is relatively well reproduced in the RegCM, but weakly in the CSM. It indicates that the RegCM is essential for the prediction of regional climate change for the East Asia region. Although the precipitation band near Japan in June is also well reproduced only in the RegCM, it is not only due to the high resolution effect but also due to the precipitation scheme used in the model.

Although the observed synoptic climate patterns in January and June are reproduced both in the RegCM and the CSM, some regional scale climate biases are found; the large cold bias in the higher latitude and the missing of Bai-u front in mainland China, which are strongly influenced by the bias in the CSM, i.e., overestimation of sea ice area, or northward shift of NPH, respectively. The SST bias contributes to the surface air temperature bias on the coast.

The biases of the 10-year mean surface air temperature and precipitation of the RegCM in four typical climate districts in Japan are within $\pm 1{ }^{\circ} \mathrm{C}$ and within $\pm 50 \%$, respectively, in both months, except some regions. Apart from the CSM bias, some 
local biases due to the performance of RegCM itself are clarified; e.g., overestimation of the weak precipitation days or unrealistic topographic rain due to the exaggerated mountain slope facing the moist southerly wind.

In the climate change simulations, the geographic distribution patterns of the changes are almost the same between the RegCM and the CSM in both months for SLP and temperature. However, the magnitude of warming is different between the models over the small islands. These discrepancies are mainly due to the fact that the surrounding ocean data are used in the interpolation from the CSM data into regional scale, when the warming is significantly different between over land (or sea ice) and ocean. On the other hand, for precipitation, the regional scale patterns of the changes are different between the RegCM and the CSM especially in June because the precipitation band near Japan is well reproduced in the RegCM both in the $1 \mathrm{CO}_{2}$ and the $2 \mathrm{CO}_{2}$ climate. This indicates that the data simply interpolated from the global climate model with coarse resolution should not be used, but instead, the RegCM results with high resolution should be used for assessing the impact of climate change in a region of such complex topography as East Asia.

In this simulation, some notable climate change features are found such as the temperature increase at higher latitudes in January or intensification of the NPH extending to the southwest in June. Although these changes are statistically significant, they occur over the bias region and their magnitudes do not exceed the bias of the simulated present climate in some region. From these results, it is clarified that the simulated climate change of East Asia by the RegCM is mainly influenced by the bias of the CSM in reproducing the present climate, such as overestimation of sea ice or northward shift of the axis of NPH.

From the analysis of the maximum and minimum air temperature change, it was clarified that the increase of the surface air temperature in Japan is mainly controlled by the warming of nearby SST. Then, in the prediction of surface air temperature change in Japan, the simulation of SST change in the global climate model plays an important role. Finally, through the analyses of the simulated results, it should be stressed that it is of utmost importance that the AOGCM information is of good quality in the prediction of regional climate change.

\section{Acknowledgments}

We thank NCAR scientists for allowing us to use the CSM in this study. We also gratefully acknowledge all of the scientists and the staff of NCAR, NEC Co. and CRIEPI who are involved in this transient run, for their great effort. We thank anonymous reviewers for their useful comments on this paper.

\section{References}

Anthes, R.A., 1977: A cumulus parameterization scheme utilizing a one-dimensional cloud model. Mon. Wea. Rev., 105, 270-286.

, E.-Y. Hsie, and Y.-H. Kuo, 1987: Description of the Penn State/NCAR Mesoscale Model version 4 (MM4). NCAR Technical Note, NCAR/ TN-282+STR, 66p.

Boville, P.R. and P.R. Gent, 1998: The NCAR climate system model, version one. J. Climate, 11, 11151130.

Christensen, J.H., B. Machenhauer, R.G. Jones, C. Schau, P.M. Ruti, M. Castro and G. Visconti, 1997: Validation of present-day regional climate simulations over Europe: LAM simulations with observed boundary conditions. Clim. Dyn., 13, 489-506.

Deque, M., P. Marquet and R.G. Jones, 1998: Simulation of climate change over Europe using a global variable resolution general circulation model. Clim. Dyn., 14, 173-189.

Dickinson, R.E., R.M. Errico, F. Giorgi, and G.T. Bates, 1989: A regional climate model for the western United States. Clim. Change, 15, 383422.

A. Henderson-Sellers, and P.J. Kennedy, 1993: Biosphere-Atmosphere Transfer Scheme (BATS) Version 1e as coupled to the NCAR Community Climate Model. NCAR Technical Note, NCAR/ TN-387+STR, 72 p.

Fukutome, S., C. Frei, D. Luthi and C. Schar, 1999: The interannual variability as a test of ground for regional climate simulations over Japan. $J$. Meteor. Soc. Japan, 77, 649-672.

Giorgi, F. and G.T. Bates, 1989: The climatological skill of a regional model over complex terrain. Mon. Wea. Rev., 117, 2325-2347.

and L. Mearns, 1991: Approaches to the simulation of regional climate change: A review. Rev. Geophys., 29, 191-216.

and ___ 1999: Introduction to special section: Regional climate modeling revisited. $J$. Geophys. Res., 104, 6335-6352.

and C. Shields, 1999: Tests of precipitation parameterizations available in the latest version of the NCAR regional climate model (RegCM) 
over the continental United States. J. Geophys. Res., 104, 6353-6375

, M.R. Marinucci, and G. Visconti, 1992: A $2 \times \mathrm{CO}_{2}$ climate change scenario over Europe generated using a limited area model nested in a general circulation model, 2, Climate change scenario. J. Geophys. Res., 97, 10011-10028. , and G.T. Bates, 1993a: Development of a second generation regional climate model (RegCM2) I: Boundary layer and radiative transfer process. Mon. Wea. Rev., 121, 2794-2813. G. De Canio, and G.T. Bates, 1993b: Development of a second generation regional climate model (RegCM2) II: Convective processes and assimilation of lateral boundary conditions. Mon. Wea. Rev., 121, 2814-2832.

C.S. Brodeur, and G.T. Bates, 1994: Regional climate change scenario over the United States produced with a nested regional climate model. J. Climate, 7, 375-399.

, J.W. Hurrell, M.R. Marinucci and M. Beniston, 1997: Elevation signal in surface climate change: A model study. J. Climate, 10, 288296.

, L.O. Mearns, C. Shields and L. McDaniel, 1998: Regional nested model simulations of present day and $2 \mathrm{xCO}_{2}$ climate over the Central Plains of the U. S.. J. Clim. Change, 40, 457-493.

, Y. Huang, K. Nishizawa, and C. Fu, 1999: A seasonal cycle simulation over East Asia and its sensitivity to radiative transfer and surface processes. J. Geophys. Res., 104, 6403-6424.

Hirakuchi, H. and F. Giorgi, 1995: Multiyear presentday and $2 \times \mathrm{CO}_{2}$ simulations of monsoon climate over eastern Asia and Japan with a regional climate model nested in a general circulation model. J. Geophys. Res., 100, 21105-21125.

Holtslag, A.A.M., E.I.F. De Bruijn, and H.-L. Pan, 1990: A high resolution air mass transformation model for short-range weather forecasting. Mon. Wea. Rev., 118, 1561-1575.

IPCC, 1990a: Climate Change: The IPCC Scientific Assessment. J.T. Houghton, G.J. Jenkins and J. J. Ephraums, (Eds.). Cambridge University Press, Cambridge, UK, 365 p.

, 1990b: Climate Change: The IPCC Impacts Assessment. W.J. McG. Tegart, G.W. Sheldon and D.C. Griffiths, (Eds.). Australian Government Publishing Service, Canberra.

, 1992: Climate Change 1992: The Supplementary Report to the IPCC Scientific Assessment. J.T. Houghton, B.A. Callander, and S.K. Varney, (Eds.). Cambridge University Press, Cambridge, UK, $200 \mathrm{pp}$.

1996: Climate Change 1995: The Science of Climate Change. J.A. Lakeman, (Ed.). Cam- bridge University Press, Cambridge, UK, 572 pp. Jones, R.G., J.M. Murphy, M. Noguer and A.B. Keen, 1997: Simulation of climate change over Europe using a nested regional climate model. II: Comparison of driving and regional model responses to a doubling of carbon dioxide. Quart. J. Roy. Meteor. Soc., 123, 265-292.

Kadokura, S, H. Kato, N. Oshima and H. Hirakuchi, 1997: Asian monsoon at the time of global warming. Prediction for doubled $\mathrm{CO}_{2}$ by NCAR-CSM. CRIEPI report, T97073, 17p. (in Japanese with English abstract)

Kato, H., 1996: A statistical method for separating urban effect trends from observed temperature data and its application to Japanese temperature records. J. Meteor. Soc. Japan, 74, 639-653.

, H. Hirakuchi, K. Nishizawa and F. Giorgi, 1999: Performance of the NCAR RegCM in the simulation of June and January climates over East Asia and the high-resolution effect of the model. J. Geophys. Res., 104, 6455-6476.

Kida, H., T. Koide, H. Sasaki, and M. Chiba, 1991: A new approach for coupling a limited area model to a GCM for regional climate simulations, $J$. Meteor. Soc. Japan, 69, 723-728.

Kiehl, J.T., J.J. Hack, G.B. Bonan, B.A. Boville, B.P. Briegleb, D.L. Williamson, and P.J. Rasch, 1996: Description of the NCAR Community Climate Model (CCM3), NCAR Tech. Note, NCAR/TN420+STR 152 pp., Boulder, CO 80307.

Laprise R., D. Caya., M. Giguere, G. Bergeron, H. Cote, J.-P. Blanchet, G.J. Boer and N.A. McFarlane, 1998: Climate and climate change in western Canada as simulated by the Canadian regional climate model. Atmosphere-Ocean, 36, 119-167.

Leung, L.R. and S.J. Ghan, 1999: Pacific Northwest climate sensitivity simulated by a regional climate model driven by a GCM. Part II: $2 \mathrm{xCO}_{2}$ simulations. J. Climate, 12, 2031-2053.

, Z.C. Zhao, Y. Luo, W.-C. Wang and H.-L Wei., 1999: Intercomparison of regional climate simulations of the 1991 summer monsoon in eastern Asia. J. Geophys. Res., 104, 6425-6454.

Liu, Y., F. Giorgi, and W.M. Washington, 1994: Simulation of summer monsoon climate over East Asia with an NCAR regional climate model. Mon. Wea. Rev., 122, 2331-2348.

Manabe, S. and T.B. Terpstra, 1974: The effects of mountains on the general circulation of the atmosphere as identified by numerical experiments. J. Atmos. Sci, 31, 3-42.

Marinucci, M.R. and F. Giorgi, 1992: A $2 \times \mathrm{CO}_{2}$ climate change scenario over Europe generated using a limited area model nested in a general circulation model, I: Present-day seasonal climate simulation. J. Geophys. Res., 97, 9989-10009. 
Maruyama, K., H. Hirakuchi, J. Tsutsui, N. Nakashiki, S. Kadokura and M. Kadoyu, 1997: Global warming projection for 125 years using NCAR CSM Coupled Model. CRIEPI report, U97034, 24p. (in Japanese with English abstract)

McGregor, J.L., 1997: Regional climate modelling. Meteor. Atmos. Phys., 63, 105-117.

Mearns, L.O., F. Giorgi, L. McDaniel, and C. Shields, 1995: Analysis of daily variability of precipitation in a nested regional climate model: Comparison with observations and doubled $\mathrm{CO}_{2}$ results. Global Planetary Change, 10, 55-78.

Nakamura, K., R. Kimura and Z. Uchijima, 1986: Climate of Japan. Nature in Japan vol 5., Iwanamishoten Co., 237p. (in Japanese)

Nishizawa, K. and F. Giorgi, 1998: Projection of the climate change over East Asia due to global warming. Development of a regional climate model based on the NCAR CCM3 radiation model. CRIEPI report, T97055, 18p. (in Japanese with English abstract)

Nitta, T., 1986: Long term variations of cloud amount in the western Pacific region. J. Meteor. Soc. Japan, 64, 373-390.

Renwick, J.A., J.J. Katzfey, K.C. Nguyen, and J.L. McGregor, 1998: Regional model simulations of New Zealand climate. J. Geophys. Res., 103, 5973-5982.

Sasaki, S., H. Kida, T. Koide, and M. Chiba, 1995: The performance of long-term integration of a limited area model with the spectral boundary coupling method. J. Meteor. Soc. Japan, 73, 165-181.

Verdecchia, M., G. Visconti, F. Giorgi, and M.R. Marinucci, 1994: Diurnal temperature range for a doubled carbon dioxide concentration experiment: analysis of possible physical mechanisms. Geophys. Res. Lett., 21, 1527-1530.

Weatherly, J.W., B.P. Briegleb, W.G. Large and J.A. Maslanik, 1998: Sea ice and Polar climate in the NCAR CSM. J. Climate, 11, 1472-1486.

Yamakawa, S., 1984: Regional and seasonal features of cold fronts in Japan and its surroundings, Geographical Rev. of Japan, 57, 154-164. 